\title{
Rostral and caudal prefrontal contribution to creativity: a meta-analysis of functional imaging data
}

\author{
Gil Gonen-Yaacovi ${ }^{1}$, Leonardo Cruz de Souza ${ }^{2,3,4}$, Richard Levy ${ }^{2,3,4,5}$, Marika Urbanski ${ }^{2,3,4,6}$, \\ Goulven Josse $e^{2,3,4}$ and Emmanuelle Volle $\mathrm{C}^{2,3,4 *}$ \\ ${ }^{1}$ Department of Psychology, Ben-Gurion University of the Negev, Beer-Sheva, Israel \\ ${ }^{2}$ Centre de Recherche de I'Institut du Cerveau et de la Moelle épinière, Université Pierre et Marie Curie-Paris 6, UMRS 975, Paris, France \\ ${ }^{3}$ Institut National de la Santé et de la Recherche Médicale, U 975, Paris, France \\ ${ }^{4}$ Centre National de la Recherche Scientifique, UMR 7225, Paris, France \\ ${ }^{5}$ AP-HP, Service de Neurologie, Hôpital Saint-Antoine, Paris, France \\ ${ }^{6}$ Service de Médecine et Réadaptation, Hôpitaux de Saint-Maurice, Saint-Maurice, France
}

\section{Edited by:}

Zbigniew R. Struzik, The University

of Tokyo, Japan

\section{Reviewed by:}

Ida Momennejad, Princeton

University, USA

Adam E. Green, Georgetown

University, USA

*Correspondence:

Emmanuelle Volle, Centre de Recherche de I'Institut du Cerveau

et de la Moelle épinière, Université

Pierre et Marie Curie-Paris 6 ,

U975/UMRS 975/UMR 7225,

Hôpital Pitié-Salpêtrière, 47, bld de

I'Hôpital, 75013 Paris, France

e-mail:emmavolle@gmail.com
Creativity is of central importance for human civilization, yet its neurocognitive bases are poorly understood. The aim of the present study was to integrate existing functional imaging data by using the meta-analysis approach. We reviewed 34 functional imaging studies that reported activation foci during tasks assumed to engage creative thinking in healthy adults. A coordinate-based meta-analysis using Activation Likelihood Estimation (ALE) first showed a set of predominantly left-hemispheric regions shared by the various creativity tasks examined. These regions included the caudal lateral prefrontal cortex (PFC), the medial and lateral rostral PFC, and the inferior parietal and posterior temporal cortices. Further analyses showed that tasks involving the combination of remote information (combination tasks) activated more anterior areas of the lateral PFC than tasks involving the free generation of unusual responses (unusual generation tasks), although both types of tasks shared caudal prefrontal areas. In addition, verbal and non-verbal tasks involved the same regions in the left caudal prefrontal, temporal, and parietal areas, but also distinct domain-oriented areas. Taken together, these findings suggest that several frontal and parieto-temporal regions may support cognitive processes shared by diverse creativity tasks, and that some regions may be specialized for distinct types of processes. In particular, the lateral PFC appeared to be organized along a rostro-caudal axis, with rostral regions involved in combining ideas creatively and more posterior regions involved in freely generating novel ideas.

Keywords: creativity, meta-analysis, divergent thinking, insight problem solving, creative thinking, functional imaging, semantic associations, originality

\section{INTRODUCTION}

Everyone has their own idea of what creativity is. While the realm of artistic creation may be the first that comes to mind, creativity is obviously a cornerstone of many domains of human activity, including science (discovery), technology (invention), and economy (innovation). However, it is not restricted to extraordinary achievements. Finding new solutions to individual problems, achieving something novel, and thinking away from pre-established ideas are all common creative processes that take place in everyday life. According to this point of view, creativity results from a set of mental functions normally found in all humans, and can be studied experimentally. From a neuroscience perspective, creativity is defined as the ability to produce work that is both novel (original) and appropriate or useful (Sternberg and Lubart, 1999; Plucker and Makel, 2010; Runco and Jaeger, 2012). Although this definition may appear reductive or simplistic, it makes experimental testing possible by allowing to form hypotheses about the cognitive processes involved in creativity, and to examine their brain correlates. However, the brain substrates of creativity have been poorly studied. In the existing research, various tasks related to four main theoretical frameworks of creativity have been used: divergent thinking, insight problem solving, combination of remote semantic associations, and artistic creativity. These studies have led to diverse results, with no consensus yet in sight (Fink et al., 2007; Arden et al., 2010; Dietrich and Kanso, 2010; Sawyer, 2011). The present meta-analysis represents an attempt to clarify this small body of literature.

Divergent thinking tasks assess the ability to generate multiple solutions to an open-ended problem that does not have a right or wrong answer (Guilford, 1950). The products of divergent tasks are evaluated according to several criteria, mainly fluency (the quantity of relevant responses), flexibility (the number of different categories of responses), originality (the degree to which responses are uncommon), and elaboration (the degree of enrichment of responses). In a review of six functional imaging studies that used divergent thinking tasks, Dietrich and Kanso (2010) highlighted the importance of the prefrontal cortex (PFC) without pinpointing a specific sub-region. Insight problem-solving tasks usually require one right answer, which 
allows rating responses as correct or incorrect. In these tasks, the solution often comes to mind with insight (an "eureka" or "aha" moment). Combining words that are remotely semantically related can also evoke an "aha" experience. One popular example of such a combination task is the Remote Associates Task, which consists of finding a word that links three stimulus words, for example, finding the word "cheese" for "rat," "blue," and "cottage" (Mednick et al., 1964b). Functional neuroimaging that uses these tasks has focused on this "aha" aspect rather than on the combinatorial or associative processes that lead to a solution. Dietrich and Kanso (2010) reviewed 11 electrophysiological and nine functional imaging studies on insight, including the Remote Associates Task, and highlighted the frequent involvement of the superior temporal gyrus (STG) and anterior cingulate cortex (ACC). Finally, six studies that examined creativity in the artistic domains of music, dancing, and painting, using ecological tasks were examined in the same review. No region was identified as necessary and sufficient for artistic creativity. Both prefrontal activation and deactivation were reported, possibly suggesting the existence of distinct types of creativity. Overall, these results are in agreement with two recent reviews of neuroimaging and electrophysiological studies of creativity (Arden et al., 2010; Fink and Benedek, 2013) that also highlighted the PFC region without converging to specific prefrontal sub-regions. Studies that used other methods in creativity research, such as voxel-based morphometry, diffusion weighted imaging, or cerebral blood flow (CBF) (Bechtereva et al., 2004; Chavez-Eakle et al., 2007; Jung et al., 2010a,b; Takeuchi et al., 2010a,b) showed a link between creative performance and the lateral frontal and parieto-temporal regions and their connections.

Despite the diversity of tasks and cognitive approaches used to measure creativity, its link with PFC activity is expected. A central role for the PFC during creative behavior is in agreement with cognitive theories according to which several prefrontal functions (such as flexibility, fluency, planning, or working memory) are key cognitive processes of creativity (Carlsson et al., 2000; Zeki, 2001; Dietrich, 2004; Mendez, 2004; Bogousslavsky, 2005; Changeux, 2005; Ward, 2007). However, the precise prefrontal sub-regions involved and their specific roles remain to be clarified. The brain location of functional imaging results was examined qualitatively in two previous reviews (Arden et al., 2010; Dietrich and Kanso, 2010), but not statistically. Consequently, the questions of whether creative thinking is statistically associated with particular sub-regions, and whether different aspects of creativity, measured by different tasks, can be related to distinct sub-regions, remain to be tested.

The aim of this meta-analysis was to identify both shared and unique neural correlates of creative thinking by performing a statistical comparison between multiple studies. We explored brain regions that are most consistently associated with creativity tasks in published functional imaging studies. The results are discussed in light of the data drawn from other methods, including patient studies. The observation of shared regions, despite the diversity of tasks and criteria used to measure creativity, would suggest the existence of a core network for creativity. In addition, in order to determine whether there are process-specific regions, experiments were categorized according to tasks (combination or unusual generation tasks) and stimuli (verbal or non-verbal). The latter distinction aimed at comparing the correlates of creativity in two distinct classical domains of cognition (verbal or non-verbal). The former distinction was based on two separate and influential cognitive theories of creativity mentioned above. The first theory emphasizes the importance of combinatorial processes in creative thinking (new combination of remote associates) and was operationalized in the Remote Associates Task by Mednick (Mednick, 1962; Mednick et al., 1964a,b; Ward and Kolomyts, 2010). Combination tasks involve associating separate and remote elements of information to form a new idea. The second theory, derived from Guilford's work (Guilford, 1950; Runco, 2010), focuses on the level of fluency, flexibility, and originality of generated ideas, and has mainly been operationalized using divergent thinking tasks, such as the Alternate Uses Task. Tasks in the unusual generation category thus consist of producing original or unusual responses to a given stimulus or situation.

\section{METHODS \\ SELECTION OF THE STUDIES}

Studies were all peer-reviewed and published in English before June 2012. The PubMed and Scopus Medline databases were searched using the following keywords in text and/or abstract/title and Boolean operators: "creativity, creative thinking, creative process, unusualness, hypothesis generation, idea generation, aha, eureka, novel ideas, original ideas, originality, insight problemsolving, insight solution, artistic" AND "brain imaging, cerebral imaging, MRI, fMRI, PET, neural correlates, cerebral correlates, brain activation, functional magnetic resonance." In order to ensure that inclusion criteria was as unbiased as possible, we did not systematically search for studies on domains that may be relevant to creativity (such as imagination, metaphors, music improvisation or expression, mental imagery, counterfactual thinking), or studies that explore various processes presumably involved in creativity (such as cognitive flexibility, inhibition of prepotent responses, working memory, planning, and so on), but such studies were included if the authors related explicitly to creativity in their work.

In addition, in order to be included in the meta-analysis, studies had to meet the following inclusion criteria: (1) using functional imaging in healthy adults, (2) reporting whole-brain results of signal changes in stereotactic space in $3 \mathrm{D}$ coordinates $(x, y, z)$ in the Montreal Neurological Institute space (MNI; Evans et al., 1993) or the Talairach space (Talairach and Tournoux, 1988), and (3) reporting the peak coordinates in these spaces. We reviewed activation contrasts between tasks performed during the scanning of one or several groups of participants. In each study, only independent contrasts were included. If several contrasts in the same study were dependent, only results from the contrast reporting the most significant maxima were included. Betweengroup comparisons based on level of expertise were not included because their interpretation is difficult in terms of neurocognitive processes.

We analyzed a total of 443 activation foci reported in 44 independent contrasts from 34 experiments carried out in 622 healthy participants, from studies listed in Table 1. 
Table 1 | List of the included studies with task description and categorization.

\begin{tabular}{|c|c|c|c|c|c|}
\hline Authors & Year & $N$ subjects & Task description & Domain of material & Task type \\
\hline Abraham et al. (contrast 1) & $2012 b$ & 19 & $\begin{array}{l}\text { Alternate Uses task (for objects) vs. } \\
\text { fluency for locations }\end{array}$ & Verbal & Unusual generation \\
\hline Abraham et al. (contrast 2) & $2012 b$ & Same as above & $\begin{array}{l}\text { Alternate Uses task (for objects) and } \\
\text { fluency for locations vs. 2-back and } \\
\text { 1-back }\end{array}$ & Verbal & Unusual generation \\
\hline Asari et al. & 2008 & 68 & $\begin{array}{l}\text { Rorschach-like test: comparison of } \\
\text { "unique" vs. "frequent" responses }\end{array}$ & Non-verbal $\left.\right|^{\S}$ & Unusual generation \\
\hline Aziz-Zadeh et al. & 2009 & 10 & $\begin{array}{l}\text { Anagram solving task in experts: } \\
\text { comparison of Aha vs. non Aha } \\
\text { responses }\end{array}$ & Verbal & None \\
\hline Aziz-Zadeh et al. & 2013 & 13 & $\begin{array}{l}\text { Assembling three distinct shapes to } \\
\text { form a new one: comparison of } \\
\text { creative vs. basic conditions }\end{array}$ & Non-verbal\$ & Combination \\
\hline Bechtereva et al. & 2004 & 16 & $\begin{array}{l}\text { Creation of stories from a set of } 16 \\
\text { remote words vs. memorize words }\end{array}$ & Verbal & None \\
\hline Bechtereva et al. & 2004 & 9 & $\begin{array}{l}\text { Produce associative verbal links } \\
\text { between words vs. words reading }\end{array}$ & Verbal & Combination \\
\hline Bengtsson et al. & 2007 & 11 & $\begin{array}{l}\text { Music improvisation vs. play from } \\
\text { memory in professional pianists }\end{array}$ & Non-verbal & None \\
\hline Berkowitz and Ansari (contrast 1) & 2008 & 13 & $\begin{array}{l}\text { Music improvisation in classical } \\
\text { pianists: melodic improvisation vs. } \\
\text { patterns }\end{array}$ & Non-verbal` & Unusual generation \\
\hline Berkowitz and Ansari (contrast 2) & 2008 & Same as above & $\begin{array}{l}\text { Music improvisation in classical } \\
\text { pianists: rhythmic improvisation vs. } \\
\text { metronome }\end{array}$ & Non-verbal & Unusual generation \\
\hline Cardillo et al. & 2012 & 20 & $\begin{array}{l}\text { Comprehension of metaphors: novel } \\
\text { vs. familiar metaphors }\end{array}$ & Verbal & Combination \\
\hline Chrysikou and Thompson-Schill & 2011 & 24 & $\begin{array}{l}\text { Alternate Uses task: generation of } \\
\text { unusual vs. usual uses for objects }\end{array}$ & Verbal & Unusual generation \\
\hline de Manzano and Ullén & 2012 & 18 & $\begin{array}{l}\text { Music improvisation in classical } \\
\text { pianists vs. music reading }\end{array}$ & Non-verbal" & None \\
\hline Ellamil et al. & 2012 & 15 & $\begin{array}{l}\text { Design of book cover illustrations: } \\
\text { ideas generation vs. evaluation phases }\end{array}$ & Non-verbal $\left.\right|^{\S}$ & None \\
\hline Fink et al. (contrast 1) & 2010 & 31 & $\begin{array}{l}\text { Alternate Uses task: alternative uses } \\
\text { vs. object characteristics }\end{array}$ & Verbal & Unusual generation \\
\hline Fink et al. (contrast 2) & 2010 & Same as above & $\begin{array}{l}\text { Alternate Uses task: incubation vs. no } \\
\text { incubation phase }\end{array}$ & Verbal & Unusual generation \\
\hline Fink et al. (contrast 3) & 2010 & Same as above & $\begin{array}{l}\text { Alternate Uses task: stimulation with } \\
\text { others ideas vs. no stimulation }\end{array}$ & Verbal & Unusual generation \\
\hline Fink et al. (contrast 1) & 2009 & 21 & Alternate Uses task vs. fixation & Verbal & Unusual generation \\
\hline Fink et al. (contrast 2) & 2009 & Same as above & Name invention vs. fixation & Verbal & Unusual generation \\
\hline Geake and Hansen & 2005 & 12 & $\begin{array}{l}\text { Fluid letter string analogy tasks: effect } \\
\text { of analogical depth }\end{array}$ & Verbal & Combination \\
\hline
\end{tabular}


Table 1 | Continued

\begin{tabular}{|c|c|c|c|c|c|}
\hline Authors & Year & $N$ subjects & Task description & Domain of material & Task type \\
\hline Goel and Vartanian (contrast 1) & 2005 & 13 & Match problems task vs. baseline & Non-verbal\$ & None \\
\hline Goel and Vartanian (contrast 2) & 2005 & Same as above & $\begin{array}{l}\text { Match problems task: successful vs. } \\
\text { unsuccessful }\end{array}$ & Non-verbal\$ & None \\
\hline Goel and Vartanian (contrast 3) & 2005 & Same as above & $\begin{array}{l}\text { Match problems task: positive } \\
\text { correlation with the number of } \\
\text { solutions }\end{array}$ & Non-verbal\$ & None \\
\hline Green et al. (contrast 1) & 2012 & 23 & $\begin{array}{l}\text { Analogy task: effect of semantic } \\
\text { distance }\end{array}$ & Verbal & Combination \\
\hline Green et al. (contrast 2) & 2012 & Same as above & Analogy task: generation vs. rest & Verbal & Combination \\
\hline Howard-Jones et al. (contrast 1) & 2005 & 8 & $\begin{array}{l}\text { Story generation from a set of three } \\
\text { words: creative vs. uncreative } \\
\text { condition }\end{array}$ & Verbal & None \\
\hline Howard-Jones et al. (contrast 2) & 2005 & Same as above & $\begin{array}{l}\text { Story generation from a set of three } \\
\text { words: unrelated vs. related words in } \\
\text { the set }\end{array}$ & Verbal & Combination \\
\hline Huang et al. & 2012 & 26 & $\begin{array}{l}\text { Imagination of pictures based on } \\
\text { given clues: creative (imagine novel } \\
\text { and interesting pictures) vs. } \\
\text { uncreative (figure out a common } \\
\text { pattern not necessarily unique) }\end{array}$ & Non-verbal\$ & Unusual generation \\
\hline Jung-Beeman et al. & 2004 & 18 & $\begin{array}{l}\text { Compound remote-associates } \\
\text { problem: Aha vs. no Aha }\end{array}$ & Verbal & Combination \\
\hline Kounios et al. & 2006 & 25 & $\begin{array}{l}\text { Compound remote-associates } \\
\text { problem:-aha vs. no aha during } \\
\text { preparation phase (before cues } \\
\text { display) }\end{array}$ & Verbal & None \\
\hline Kowatari et al. (study 1) & 2009 & 20 & $\begin{array}{l}\text { Design of a new tool (a pen) by } \\
\text { experts }\end{array}$ & Non-verbal $\left.\right|^{\S}$ & Unusual generation \\
\hline Kowatari et al. (study 2) & 2009 & 20 & $\begin{array}{l}\text { Design of a new tool (a pen) by } \\
\text { novices }\end{array}$ & Non-verbal\$ & Unusual generation \\
\hline Kröger et al. & 2012 & 19 & $\begin{array}{l}\text { Modified Alternate Uses Task } \\
\text { (Conceptual expansion: judgment of } \\
\text { word pairs according to unusualness } \\
\text { and appropriateness) }\end{array}$ & Verbal & Combination \\
\hline Limb and Braun & 2008 & 6 & $\begin{array}{l}\text { Music improvisation vs. over-learned } \\
\text { (jazz and scale) in expert pianists }\end{array}$ & Non-verbal` & None \\
\hline Luo et al. & 2004 & 15 & $\begin{array}{l}\text { Solving ambiguous sentences with } \\
\text { solution cues: aha vs. no aha }\end{array}$ & Verbal & Combination \\
\hline Mashal et al. & 2007 & 15 & $\begin{array}{l}\text { Metaphor: novel metaphors vs. } \\
\text { unrelated words }\end{array}$ & Verbal & Combination \\
\hline Qiu et al. & 2010 & 16 & $\begin{array}{l}\text { Chinese logogriphs: Aha vs. no Aha } \\
\text { problem solving }\end{array}$ & Verbal & Combination \\
\hline Rutter et al. & 2012 & 18 & $\begin{array}{l}\text { Conceptual expansion (judgment of } \\
\text { sentences according to unusualness } \\
\text { and appropriateness) }\end{array}$ & Verbal & Combination \\
\hline
\end{tabular}


Table 1 | Continued

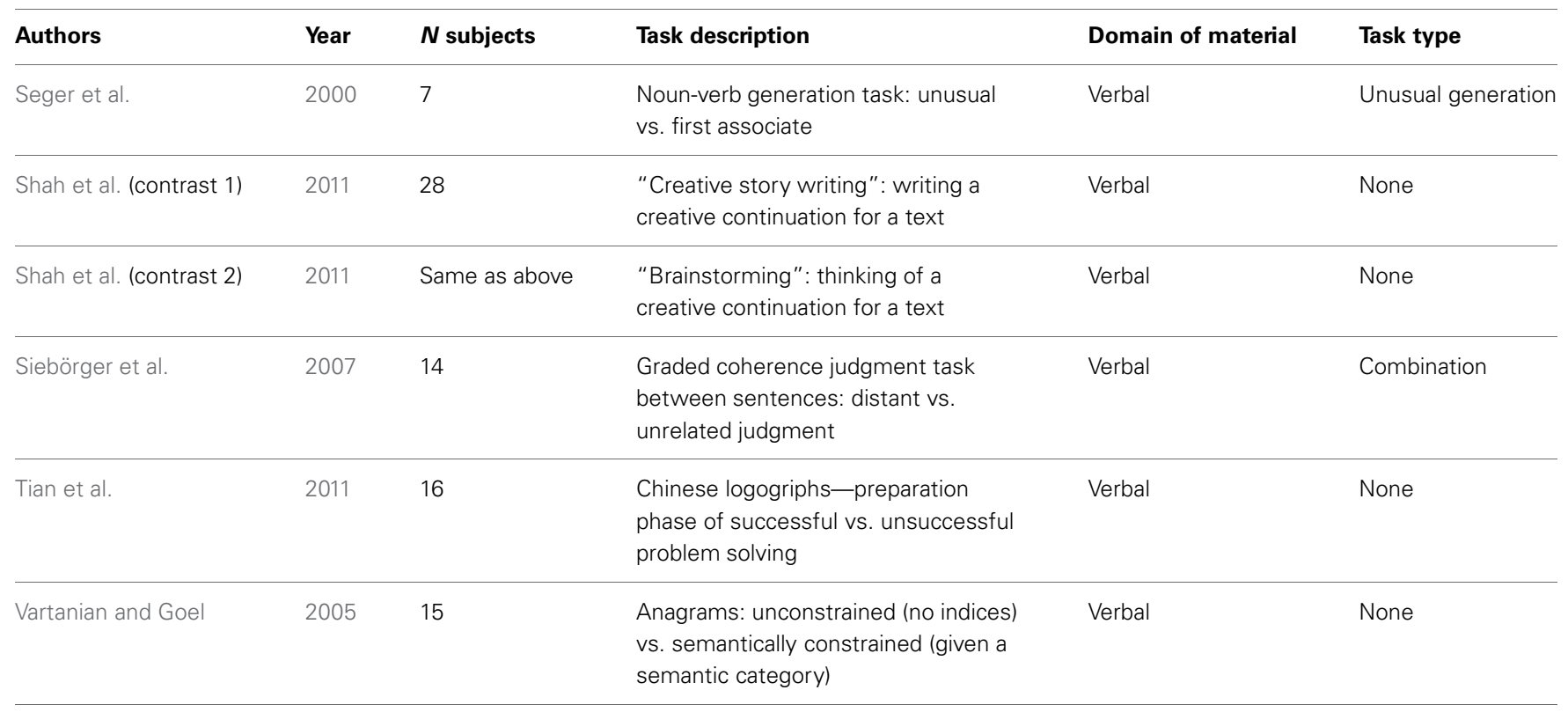

${ }^{\S}$ visual domain;" music.

\section{CONTRAST CATEGORIES (TABLE 1)}

Each study was categorized in order to look for dissociations between networks associated with distinct creativity domains or operations. As it was difficult to group heterogeneous tasks in categories based on task used, they were classified into larger categories based on type of process involved (for example, combination of information vs. self-generation of unusual responses) and domain of information processing (verbal or not) used. First, we categorized each experiment according to the type of creativity processes: combination or free unusual generation tasks. Tasks that involved an explicit request to freely generate an unusual response were gathered in the "unusual generation" category, while those that required the combination of separate and remote elements were categorized as "combination." Tasks that did not fall into one of these categories were not included, leaving 29 experiments in this sub-analysis.

The second classification was based on the verbal or nonverbal nature of the stimuli used. The non-verbal category included visual and musical domains. While these domains are different, they were gathered into the non-verbal category because the number of experiments in each domain separately was insufficient for statistical testing.

All contrasts were classified according to these categories by two double-blind authors (GGY, EV). The few disagreements that occurred were all solved by discussion between the co-authors.

\section{ALE METHODS}

\section{General principles}

We performed a meta-analysis of functional neuroimaging data on creativity using Activation Likelihood Estimation (GingerALE) software (http://brainmap.org/ale/cli.html; Laird et al., 2005; Eickhoff et al., 2009, 2012; Turkeltaub et al.,
2012). ALE is a coordinate-based meta-analysis method that uses published activation peaks reported in functional imaging studies in a normalized coordinate referential. ALE delineates the regions in the brain where convergence across all included studies is higher than would be expected by chance (null distribution of randomly generated activation likelihoods) (Eickhoff et al., 2009). In other words, ALE evaluates the "inter-experiment" reliability of the involvement of brain regions in given processes-in this case in creativity tasks.

\section{Global analysis}

The ALE analyses were conducted using the GingerALE software v2.2 (www.brainmap.org; Eickhoff et al., 2009, 2012; Turkeltaub et al., 2012). Coordinates collected from studies that were reported in Talairach space were converted into the MNI space using the tal2mni algorithm implemented in Matlab (http:// imaging.mrc-cbu.cam.ac.uk/imaging/MniTalairach). In the first step, activation foci from each included study were modeled as Gaussian distributions and merged into a single 3D volume. To address the problem of the independence of observation within the same study, we used the modified ALE algorithm (Turkeltaub et al., 2012) and organized datasets according to subject groups. The algorithm also modeled spatial uncertainty (Eickhoff et al., 2009, 2012) —and thus probability distributionof each focus, using an estimation of the inter-subject and inter-laboratory variability typically observed in neuroimaging experiments, rather than a pre-specified full-width half maximum (FWHM). Thus, the number of participants in a given study influenced the spatial extent of the Gaussian function used. GingerALE first modeled the probability of activation over all studies at each spatial point in the brain, returning localized "activation likelihood estimates" or ALE values. 
In a second step, ALE values were compared to a null distribution created from simulated datasets with randomly placed foci in order to identify significantly activated clusters. ALE maps were calculated using 10,000 permutations. We used a cluster correction for multiple comparisons (Eickhoff et al., 2012) with a false discovery rate (FDR) corrected threshold at $p<0.05$ for cluster-formation and then a $p<0.05$ for cluster thresholding. Only clusters with a size exceeding the cluster size recommended by ALE were reported. We used an extentthreshold because cluster-level inference may represent a compromise between uncorrected thresholding with additional arbitrary extent correction and voxel-level corrected inference. Moreover, cluster-level thresholding seems to provide a better balance between sensitivity and specificity than the highly conservative voxel-level family-wise error (FWE) correction (Eickhoff et al., 2012).

\section{Focused sub-analyses}

In order to analyse specific task categories, an ALE analysis was first performed separately for each task category (combination and unusual generation tasks, verbal and non-verbal). We proceeded as described for the global analysis (with a cluster thresholding), but entered only selected corresponding foci.

\section{Task comparisons}

Differences between task categories were tested by first performing an ALE analysis separately for each condition (thresholded at $p<0.05$ uncorrected) and then computing the voxel-wise difference between the resulting ALE maps (Laird et al., 2005). The difference in ALE value between two ALE maps was computed at each voxel, and statistical significance was tested using permutations. An FDR correction at $p<0.05$ was used with a minimum cluster size of $200 \mathrm{~mm}^{3}$ in order to address the problem of multiple comparisons.

\section{ALE results}

Anatomical labels of final cluster locations were provided by the Talairach Daemon (http://www.talairach.org/daemon.html) and available as a GingerALE output. Each ALE map was visualized using Mango (http://ric.uthscsa.edu/mango) and Anatomist (http://brainvisa.info/), and was overlaid on the anatomical Colin27 Template for visual inspection and representation purposes using Anatomist.

\section{RESULTS \\ ALL STUDIES (SEE TABLE 2, FIGURE 1)}

The global ALE map revealed a network consistently associated with various creativity tasks, including the bilateral inferior and left superior PFC (BA 44, 47, 46, 9, 10), the medial PFC (BA 6, 9), the bilateral ACC and insula, the left anterior (BA 37) and posterior lateral temporal gyri (BA 22, 37), the right fusiform gyrus, the left supramarginal gyrus (BA 40) and precuneus (BA 7), the bilateral occipital cortex, the bilateral anterior and posterior cerebellum, and the left thalamus.

\section{COMBINATION vS. UNUSUAL GENERATION TASKS (TABLES 3, 4, 5 AND} FIGURES 2A,B)

The ALE map that resulted from grouping combination tasks (Figure 2A, Table 3) revealed a bilateral and predominantly left network involving the lateral PFC (BA 45, 47, 46), including its rostrolateral part (BA 10), the left precentral region (BA 6), the left ACC (BA 24/32), the bilateral insula, the posterior temporal gyri (BA 22, 39), the left inferior parietal lobule (BA 40), the right superior parietal lobule (BA 7) and bilateral precuneus (BA 7), the fusiform and lingual gyri, and the cerebellum (lobule VI).

The ALE map that resulted from grouping unusual generation tasks (Figure 2A, Table 4) revealed a network that included the left inferior and middle frontal gyrus (BA 9, 44, 46), the left rostromedial PFC (BA 10), the bilateral precentral gyrus (BA 6), the left anterior and right posterior cingulate cortex, the bilateral fusiform gyrus (BA 37), the right temporal pole (BA 38), the left inferior parietal lobule (BA 40) and precuneus (BA 7), bilateral cerebellar lobules IV and V, the occipital cortex, and the left thalamus.

Combination and generation tasks overlapped in several focused regions, including the inferior frontal junction (IFJ), the inferior frontal gyrus (IFG), the posterior middle frontal gyrus, the parieto-occipital cortex, and the medial wall (Figure 2A).

When comparing these two task categories statistically (Figure 2B, Table 5), ALE showed regions more consistently associated with combination than generation tasks. These regions were located in the left rostrolateral PFC (BA 10) and the left inferior and middle frontal gyri (BA 45, 46), in the right IFG (BA 45, 46) and insula, in the left posterior middle temporal gyrus (BA $21 / 37$ ), and in the left posterior parietal region.

Conversely, ALE showed regions that were more strongly associated with generation than combination tasks within the bilateral cerebellum (Lobules IV, V, VI, and VIIb), the bilateral thalamus, the left inferior parietal lobule (BA 40), the right posterior cingulate (BA 29), and the left middle frontal gyrus (BA 9).

\section{VERBAL vs. NON-VERBAL TASKS (TABLES 6, 7, 8 AND FIGURES 3A,B)}

For verbal tasks only (Figure 3A, Table 6), significant activation was found bilaterally with a left dominance within lateral prefrontal regions, including the IFG (BA 44, 47), the middle frontal gyrus (BA 8, 9, 46), and extending into the rostral PFC (medial and lateral BA 10), and the superior frontal gyrus (BA 6,8). Additional regions were observed in the left anterior temporal fusiform gyrus and in the posterior part of the lateral temporal region extending into the inferior parietal lobule (BA 39/40), in the middle temporal gyrus caudally, in the left fusiform gyrus, and the anterior STG. The bilateral insula, superior parietal lobule, cerebellum, and subcortical structures were also involved.

For non-verbal tasks only (Figure 3A, Table 7), significant activation was found bilaterally, but predominantly in the left inferior (BA 47) and superior (BA 9, 46) parts of the lateral PFC, left rostromedial PFC (BA10), right and left precentral and medial BA 6, left ACC and insula, right and left occipital cortex, inferior (BA 40) and right superior (BA 7) parietal lobules, right fusiform gyrus (BA 37), and cerebellum (lobules IV, V, VI, VIII).

Verbal and non-verbal tasks overlapped in several focused left regions, including the IFJ, the posterior IFG, the parieto-occipital 
Table 2 | Locations of clusters with significant ALE values for the global analysis.

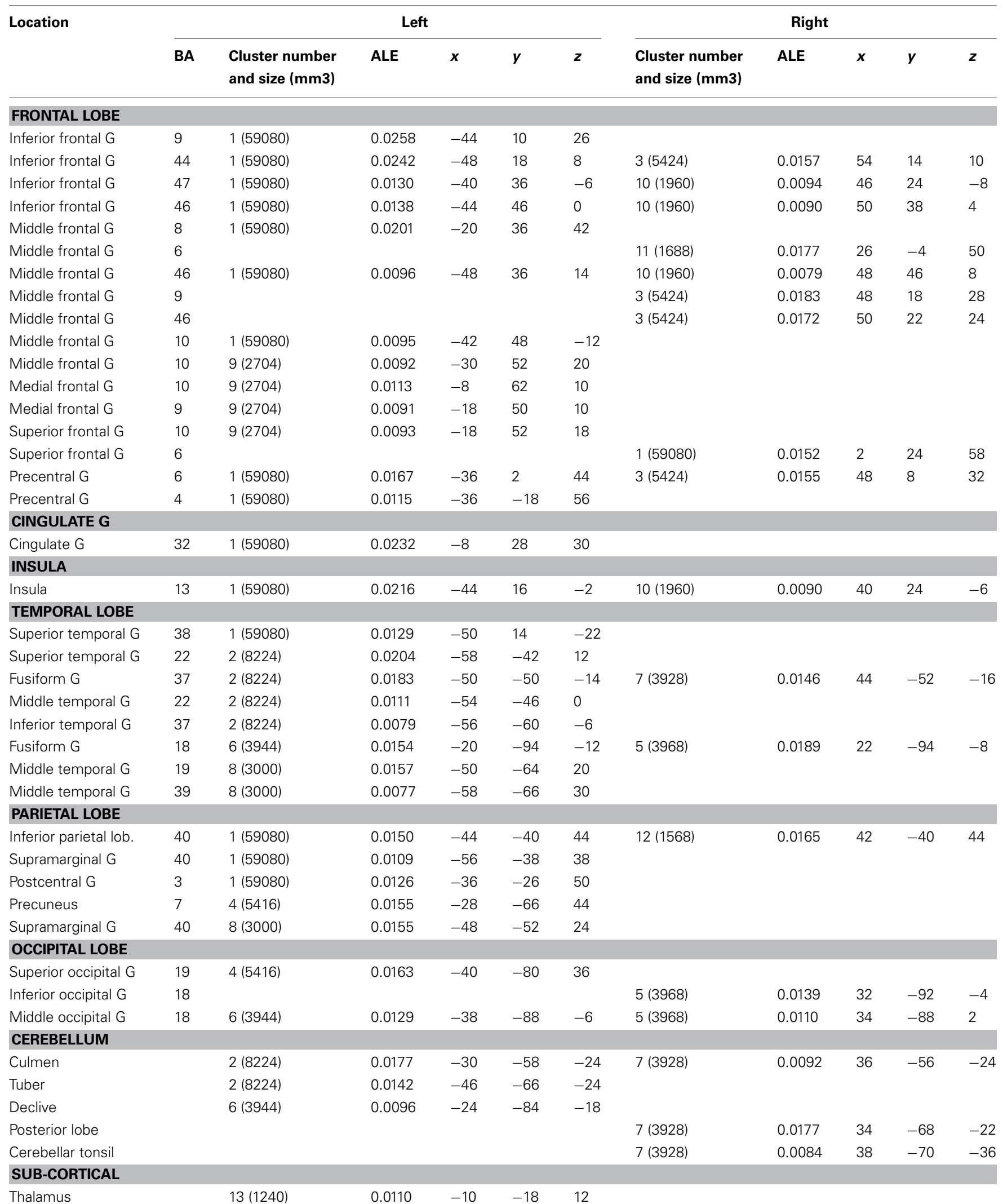

Columns number 3-7 represent data associated with the left hemisphere and 7-12 represent data associated with the right hemisphere. Abbreviations: BA, approximate Brodmann area; ALE, activation likelihood estimation; G, gyrus; Lob, lobule; x, y, z coordinates, peak voxel in the Montreal Neurologic Institute (MNI) space. 
cortex, the posterior middle frontal gyrus, the medial wall, and the cerebellum (Figure 3A).

When comparing these two task domains statistically (Figure 3B, Table 8), ALE revealed some regions to be more consistently associated with verbal tasks: mainly the left and right lateral PFC (BA 8, 9, 44, 46, 47, 10). Additional regions in the left ACC, the left posterior STG (BA 22/37), the right lingual gyrus, and the left thalamus were also observed.

The reverse contrast showed a few regions more associated with non-verbal than verbal tasks, within the right and left premotor regions (medial and lateral BA 6), the left middle frontal gyrus (BA 9), and the left occipital cortex.

\section{DISCUSSION}

\section{GENERAL FEATURES OF THE SHARED CREATIVITY NETWORK}

To our knowledge, the present study is the first quantitative metaanalysis to focus on creativity tasks. It reveals, despite the variety of tasks employed (Table 1), a statistical convergence across experiments in a set of brain regions (Figure 1): the caudal part of the lateral PFC, both ventrally and dorsally, the medial and lateral portion of the left rostral PFC, the inferior parietal lobule, and the lateral temporal gyrus. In this set of brain regions, the PFC is of central importance. This finding is in agreement with previous reviews (Fink et al., 2007; Dietrich and Kanso, 2010) as well as with the small number of lesion studies that has examined the cerebral bases of creativity in neurological patients (Miller and Tippett, 1996; Reverberi et al., 2005; de Souza et al., 2010; Shamay-Tsoory et al., 2011; Abraham et al., 2012a). In particular, Shamay-Tsoory et al. (2011) and Abraham et al. (2012a) demonstrated that damage to the rostral PFC impaired performance on divergent creativity tests such as the Alternate Uses test and the Torrance Test of Creative Thinking (TTCT, Torrance, 1979). The present meta-analysis similarly pointed to the rostral PFC (BA 10) as an important region for creativity tasks.

This set of brain regions shared by functional imaging studies is also consistent with those observed using other methods, in both the prefrontal and posterior regions (Chavez-Eakle et al., 2007; de Souza et al., 2010). For instance, de Souza et al. (2010) used SPECT to examine 17 patients with behavioral variant of fronto-temporal lobar degeneration (bvFTD), and showed brain regions in which perfusion correlated with creativity performance on the TTCT. Several of the reported regions overlapped or were very close to the ones shown in the present meta-analysis, in particular in the left IFG (BA 47), the left posterior inferior and middle temporal gyri (BA 37), the left inferior parietal lobule (BA39/40), and the left precuneus (BA 23).
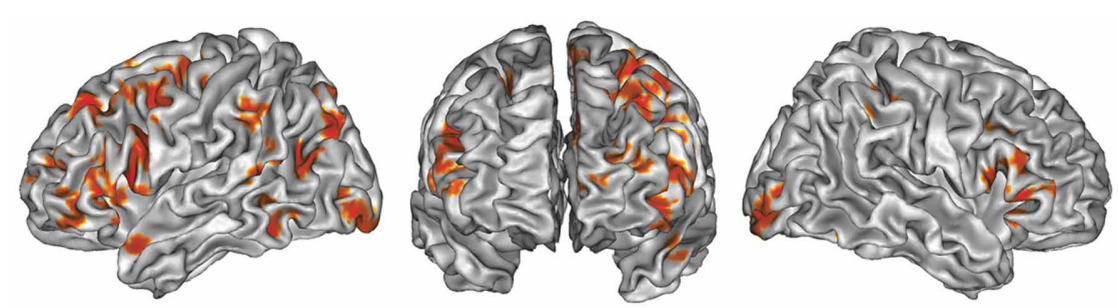

FIGURE 1 | ALE map of all foci, thresholded at a whole-brain cluster-level corrected $p<0.05$. Activations are displayed on the surface rendering of the Colin27 template (Holmes et al., 1998) in the MNI space.
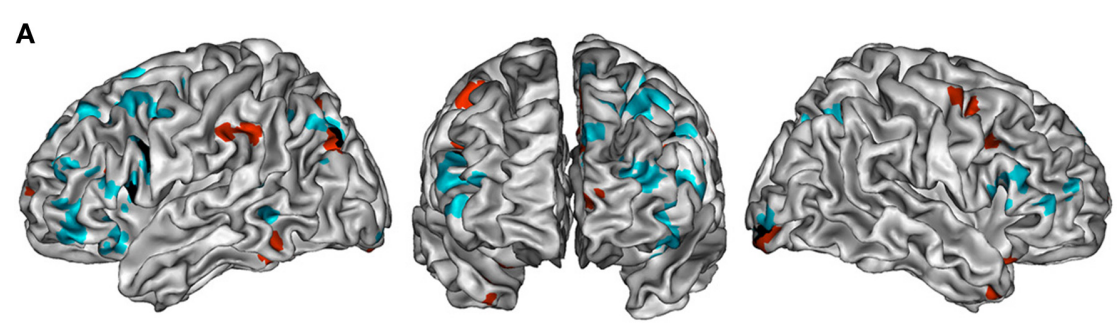

B
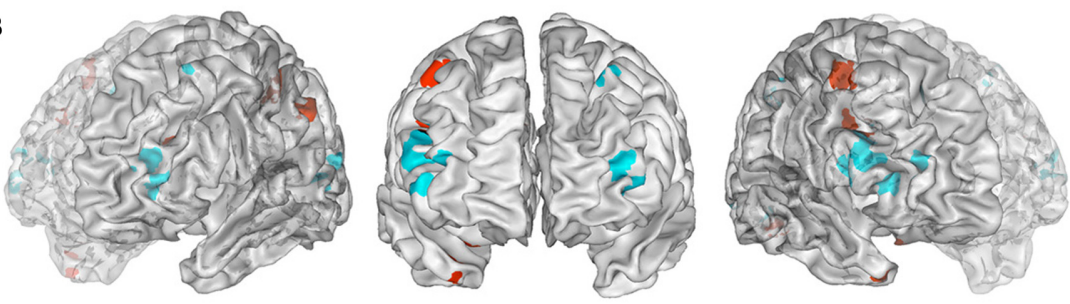

FIGURE 2 | (A) ALE maps of combination task foci (in cyan) and generation task foci (in red). Overlaps between maps are shown in black. All maps were thresholded at a whole-brain cluster-level corrected $p<0.05$. (B) ALE maps resulting from contrast studies of combination vs. generation tasks foci (in cyan) and generation vs. combination task foci (in red). These contrast maps were thresholded at a whole-brain FDR corrected $p<0.05$. In (A,B), ALE maps are displayed on a surface rendering of the Colin27 template (Holmes et al., 1998) in the MNI space. 
Table 3 | Locations of clusters with significant ALE values for combination tasks.

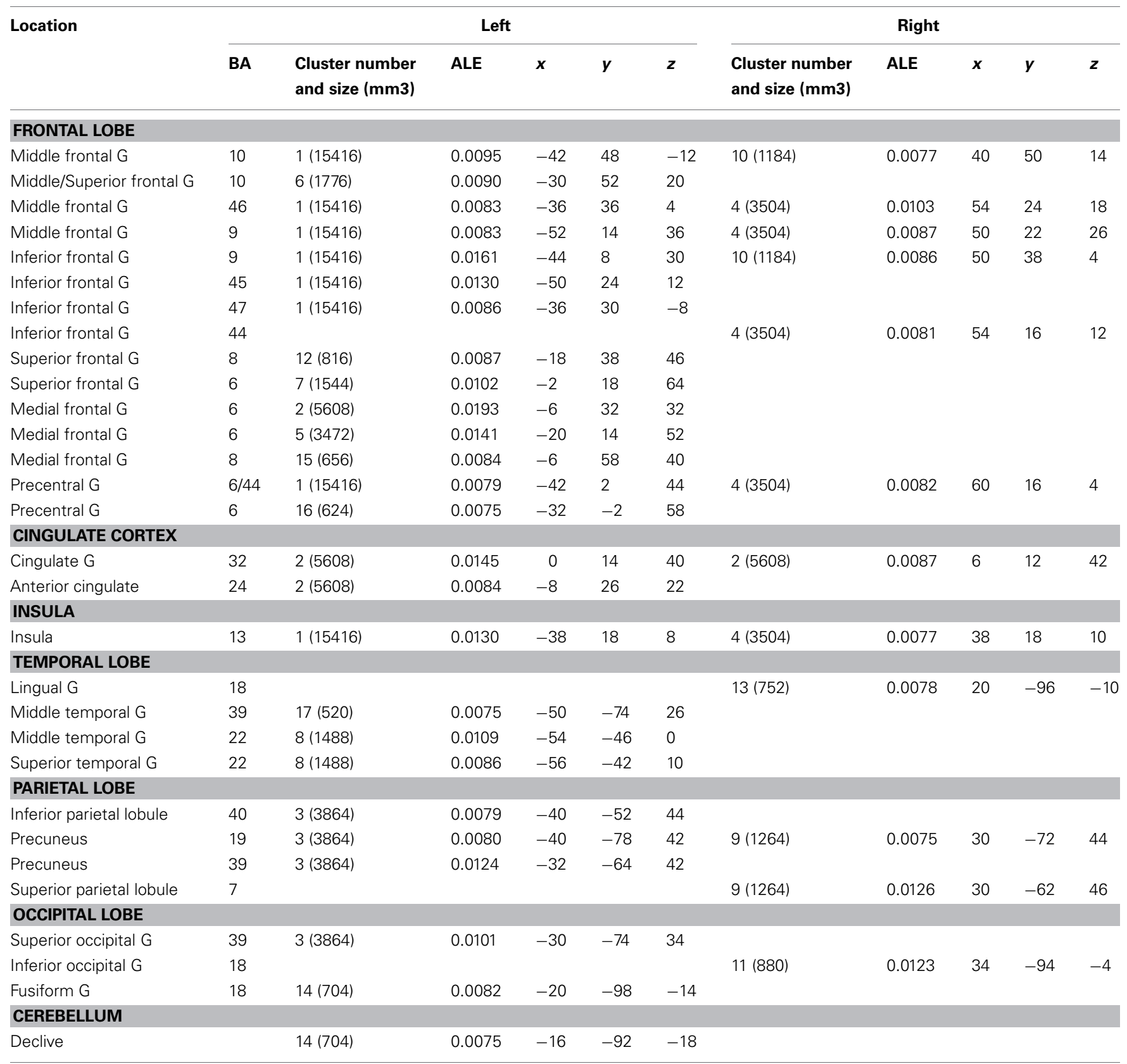

Columns number 3-7 represent data associated with the left hemisphere and 7-12 represent data associated with the right hemisphere. Abbreviations: BA, approximate Brodmann area; ALE, activation likelihood estimation; G, gyrus; x, y, z coordinates, peak voxel in the Montreal Neurologic Institute (MNI) space.

The shared creativity network evidenced here includes regions usually associated with cognitive rather than affective processing. This finding suggests that this set of brain regions supports cognitive processes rather than affective, conative, or motivational processes (Lubart, 2003). This does not imply that the latter processes are not involved in creative thinking. One should keep in mind that this review was specifically designed to investigate the cognitive aspects of creative thinking rather than affective factors.

The brain regions shared by creativity tasks appear to be predominantly distributed in the left hemisphere (Figure 1).
When comparing the number of left and right foci reported in the reviewed studies, the number of left foci $(n=266)$ was significantly greater than the right $(n=173)$ ones [paired $t$-test: $t_{(33)}=3.43, p=0.002$ ]. This predominance of left colocalizations, which was also observed in previous studies (Arden et al., 2010; de Souza et al., 2010; Dietrich and Kanso, 2010), does not support the hypothesis of right dominance for creativity (Bowden and Jung-Beeman, 2003; Jung-Beeman et al., 2004; Friedman and Forster, 2005; Howard-Jones et al., 2005; Arden et al., 2010; Dietrich and Kanso, 2010). Furthermore, the 
Table 4 | Locations of clusters with significant ALE values for unusual generation tasks.

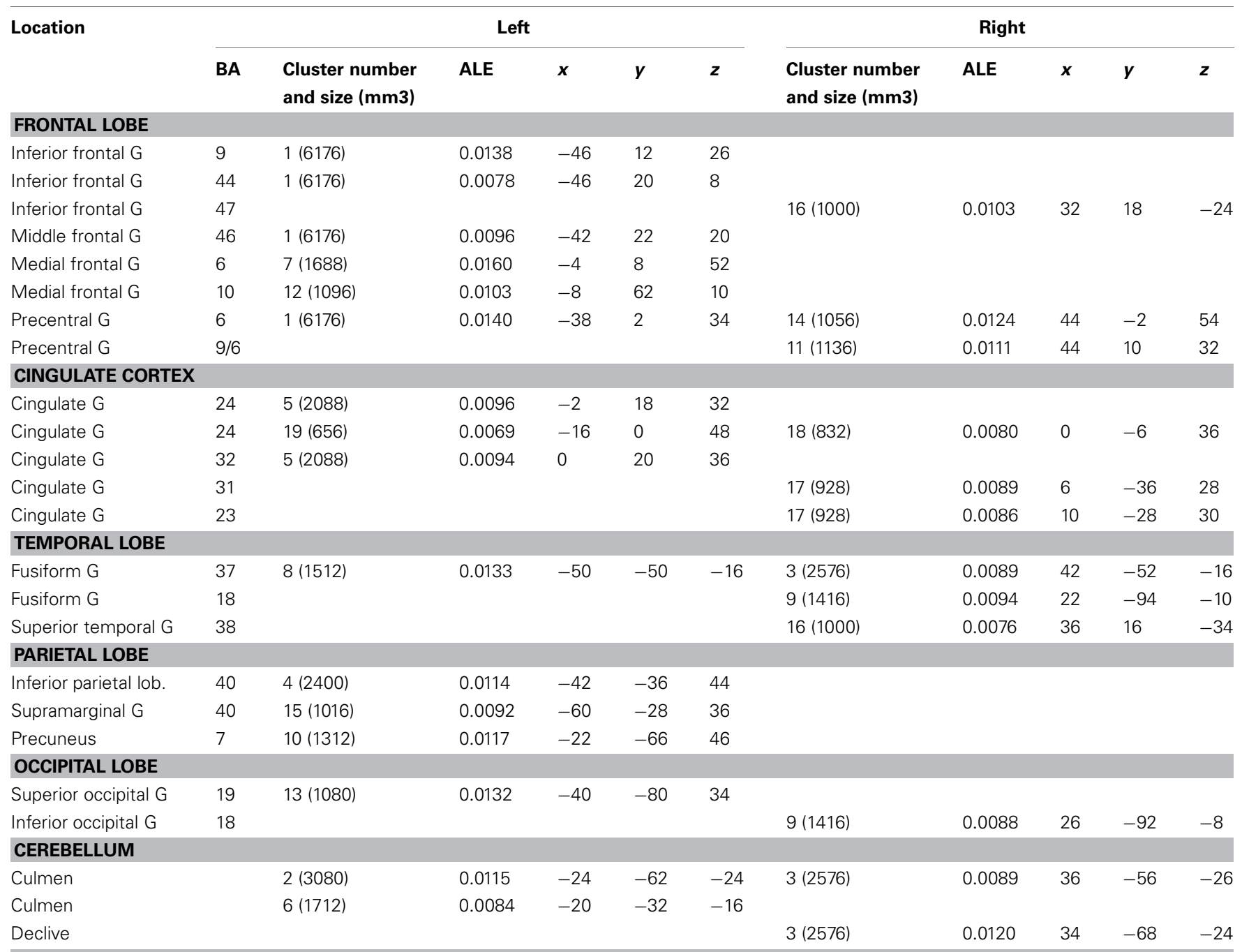

\section{SUB-CORTICAL}

Thalamus

$6(1712)$

0.0132

$-16$

$-30 \quad-4$

Columns number 3-7 represent data associated with the left hemisphere and 7-12 represent data associated with the right hemisphere. Abbreviations: BA, approximate Brodmann area; ALE, activation likelihood estimation; $G$, gyrus; $x, y, z$ coordinates, peak voxel in the Montreal Neurologic Institute (MNI) space.

left—but not right—dorsolateral PFC and left anterior temporal lobe have been shown to be critical for creativity tasks in brain stimulation studies (Cerruti and Schlaug, 2009; Chi and Snyder, 2011, 2012; Metuki et al., 2012). The leftward asymmetry observed in the present study is unlikely due to a domain effect, since both verbal and non-verbal stimuli were associated with a left-dominant network $(60 \%$ of the foci were left-sided in both verbal and non-verbal experiments). Overall, available evidence shows that both hemispheres are involved in creative thinking, and it is possible that right regions are specialized for specific processes (see further discussion below in relation to the combination vs. generation comparison).

\section{SEMANTIC AND EXECUTIVE ROLES OF THE SHARED CREATIVITY NETWORK}

The shared creativity regions evidenced by this meta-analysis include areas involved in semantic processing (Buckner et al.,
2008; Binder et al., 2009; Price, 2010; Seghier et al., 2010; Vigneau et al., 2010): the IFG (BA47), the left posterior parietal lobule, and the left posterior part of the lateral middle temporal region. Some of these regions, namely the left IFG and posterior part of the left lateral temporal cortex, were more associated with verbal than non-verbal tasks in the subsequent analysis, reinforcing the hypothesis that these regions fulfil the semantic requirements of creativity tasks. The left IFG is indeed thought to play a crucial role in the controlled retrieval of information in semantic memory and/or in the selection of semantic associates in competition during retrieval (Thompson-Schill et al., 1997; Wagner et al., 2001; Thompson-Schill, 2003; Badre and Wagner, 2004, 2007; Kan and Thompson-Schill, 2004; Martin and Cheng, 2006; Thompson-Schill and Botvinick, 2006). According to its multimodal integrative functions and its role in semantic memory (Binder et al., 2009), the posterior parietal lobule (BA 39) may be essential to the integration of different types of semantic 
Table 5 | Locations of clusters with significant ALE values for the contrast of combination vs. generation tasks and the reverse contrast.

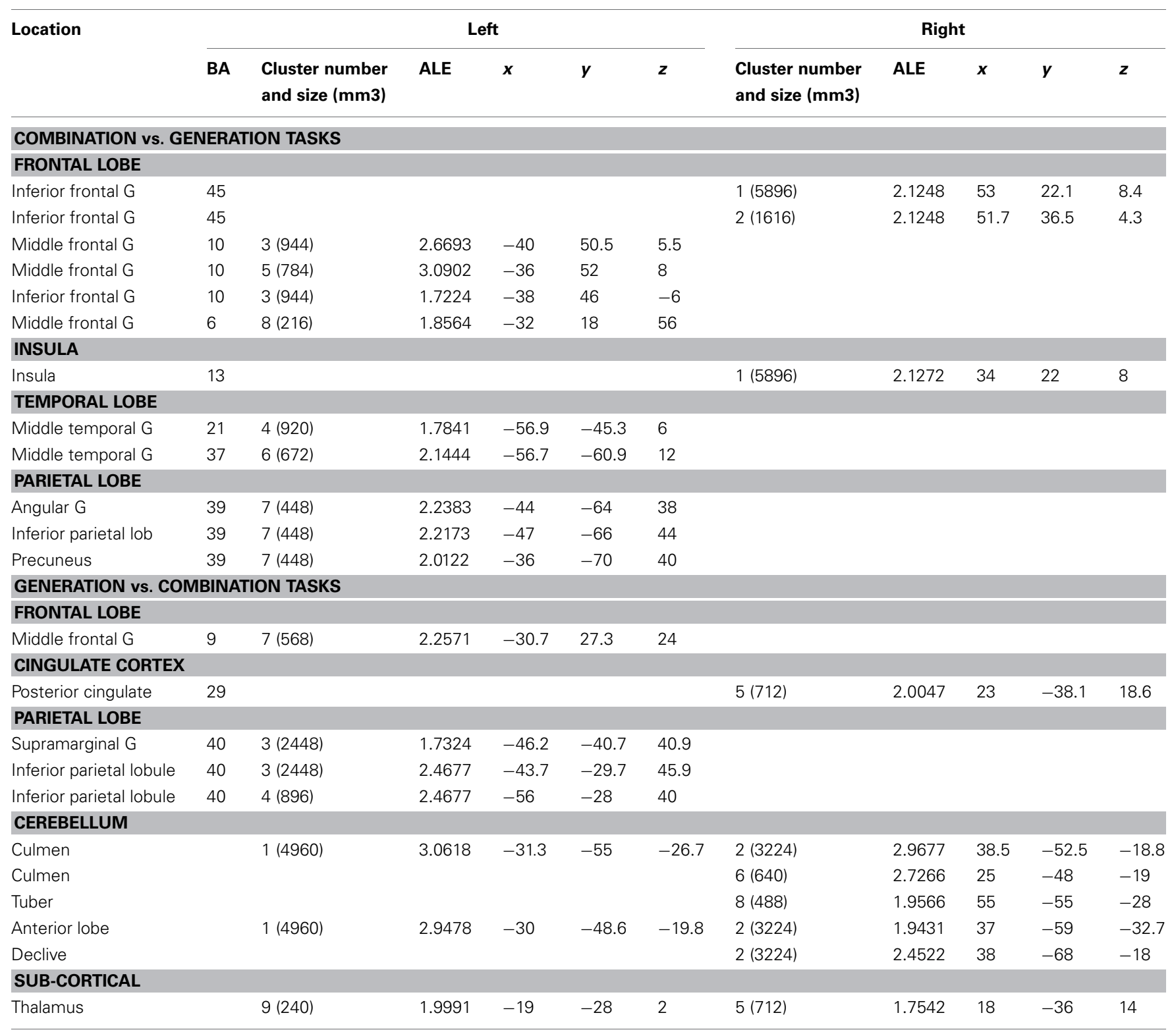

Columns number 3-7 represent data associated with the left hemisphere and 7-12 represent data associated with the right hemisphere. Abbreviations: BA, approximate Brodmann area; ALE, activation likelihood estimation; x, y, z coordinates, peak voxel in the Montreal Neurologic Institute (MNI) space.

information. The lateral temporal cortex has been associated with the activation of semantic concepts and the integration of their meaning (Price, 2010).

The shared creativity network includes several prefrontalparietal sub-regions. Parieto-prefrontal networks have also been found associated with fluid reasoning (e.g., the P-FIT theory from Jung and Haier, 2007) and executive functions, though their exact location is difficult to compare to the current results. Among the present prefrontal regions, overlaps were found between taskdependent maps in several discrete regions (overlap between combination and generation maps in Figure 2A, overlap between verbal and non-verbal tasks maps in Figure 3A). Both overlaps included a frontal region located in the caudal part of the IFG and the IFJ, extending to the adjacent middle frontal gyrus (BA $44,45 / 47)$. This region has been associated with several executive processes, including cognitive control (Koechlin et al., 2003; Derrfuss et al., 2005; Azuar et al., 2010), inhibition, and flexibility (Miller and Tippett, 1996; Aron et al., 2003; Rieger et al., 2003; Derrfuss et al., 2005; Picton et al., 2007; Volle et al., 2012), fluency (Perret, 1974; Bates et al., 2003; Krainik et al., 2003; Hillis et al., 2004; Kinkingnehun et al., 2007), and working memory (Goldman-Rakic, 1987; Duncan and Owen, 2000; Mottaghy et al., 2002; Curtis and D'Esposito, 2003; Sakai and Passingham, 2003; Courtney, 2004; Volle et al., 2005, 2008; Mohr et al., 2006; Mottaghy, 2006; Postle, 2006; Sala and Courtney, 2007; Tsuchida and Fellows, 2009). 


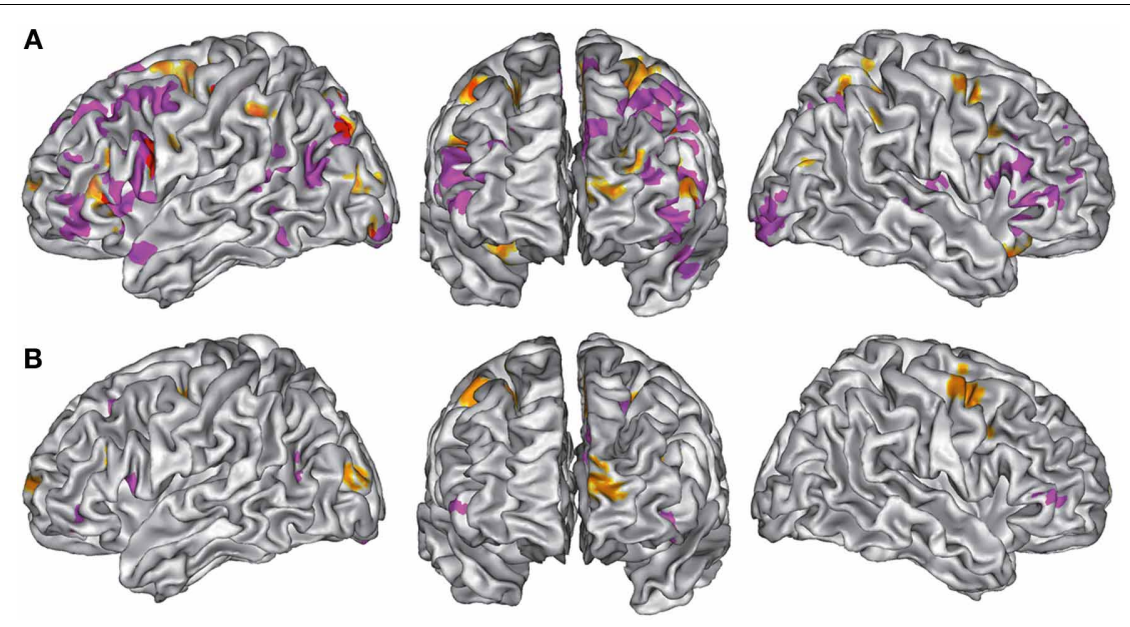

FIGURE 3 | (A) ALE maps of verbal task foci (in purple) and non-verbal task foci (in orange). Overlaps between maps are shown in red. All maps were thresholded at a whole-brain cluster-level corrected $p<0.05$. (B) ALE maps resulting from contrast studies of verbal vs. non-verbal task foci (in purple) and non-verbal vs. verbal task foci (in orange). These contrast maps were thresholded at a whole-brain FDR corrected $p<0.05$. In (A,B), ALE maps are displayed on a surface rendering of the Colin27 template (Holmes et al., 1998) in the MNI space.
Although this meta-analgfysis was not designed to determine the specific executive processes supported by these regions, it is nevertheless interesting to consider their link with creativity tasks, as several theoretical frameworks rely on the involvement of the executive processes in creative thinking (Carlsson et al., 2000; Dietrich, 2004; Bogousslavsky, 2005; Changeux, 2005). Among these processes, fluency is critical for divergent thinking tasks, such as the TTCT. Chavez-Eakle et al. (2007) showed a region within the left IFG (BA 47, 11) in which CBF correlated with fluency performance on the TTCT in healthy subjects. More specifically, among the criteria measured by the TTCT, the inferior frontal region was related to the fluency (as well as flexibility) aspects of the task, whereas $\mathrm{CBF}$ in a more anterior region in the rostral PFC (BA 10) co-varied with the originality of responses. Cognitive flexibility (set shifting and task switching tasks) has been consistently associated with the IFJ, together with the posterior parietal cortex (Derrfuss et al., 2005; Kim et al., 2011). In contrast to classical set shifting or task switching paradigms, shifts in creativity tasks are not specified by an instruction or by feedback, but are initiated spontaneously by the individual. In relation to spontaneous flexibility, previous patient studies (Miller and Tippett, 1996; Goel and Grafman, 2000) have suggested a role for the right inferior frontal region in hypothesis generation with set-shift transformation-processes that may be necessary in most creativity tasks. The lateral PFC, and especially the IFJ and/or right IFG have also been associated with inhibition of prepotent but inappropriate responses and switching to an alternative response (Miller and Tippett, 1996; Garavan et al., 1999; Konishi et al., 1999; Liddle et al., 2001; Menon et al., 2001; Aron et al., 2003; Rieger et al., 2003; Brass et al., 2005; Derrfuss et al., 2005; Picton et al., 2007; Xue et al., 2008; Kenner et al., 2010; Walther et al., 2010; Volle et al., 2012).

Cognitive flexibility and inhibition of prepotent responses could be related to processes that enable thinking away from conventional or constrained ideas (Munakata et al., 2011), a fundamental principle of most creativity tasks, including divergent thinking and problem-solving tasks. In divergent thinking tasks, originality depends on the ability to provide unusual answers and may require the suppression of more obvious responses. In problem-solving tasks, problems are typically biased by constraints that are implicitly induced by the problem and that prevent participants from considering and evaluating the correct solutions (Knoblich et al., 1999; Frith, 2000; see also Reverberi et al., 2005; Chi and Snyder, 2011). Relaxing constraints in the semantic domain, for instance in a sentence completion task (Burgess and Shallice, 1997), also relies on the lateral PFC (Nathaniel-James and Frith, 2002). Further exploration is needed to determine whether thinking away from constraints and more classical executive functions, namely cognitive flexibility and inhibition, rely on similar lateral prefrontal regions (the IFG or middle frontal gyrus).

Overall, several regions-especially in the lateral PFCmay support the semantic and executive processes involved in various creativity tasks. These processes may participate in knowledge activation and its control, enabling ideation (Table 9).

\section{SPECIALIZATIONS OF DIFFERENT REGIONS FOR DISTINCT TASK DEMANDS \\ Regions showing greater activity for combination than unusual generation tasks (Table 9)}

This meta-analysis also suggests that specific brain regions may support specific creative tasks, with combination and generation tasks activating partly non-overlapping brain regions (Figure 2). The rostral portion of the PFC (BA 10) was particularly sensitive to this distinction. Statistical comparison between task categories (Figure 2B) showed that combination tasks, more than the other task types, recruited the lateral rostral PFC together with the posterior lateral temporal and temporo-parietal regions. The lateral rostral PFC is generally activated by tasks that require integration of multiple relations (Christoff et al., 2001; Kroger et al., 
Table 6 | Locations of clusters with significant ALE values for verbal tasks.

\begin{tabular}{|c|c|c|c|c|c|c|c|c|c|c|c|}
\hline Location & \multicolumn{6}{|c|}{ Left } & \multicolumn{5}{|c|}{ Right } \\
\hline \multicolumn{12}{|l|}{ FRONTAL LOBE } \\
\hline Inferior frontal G & 44 & 1 (37792) & 0.0240 & -48 & 18 & 8 & 4 (3832) & 0.0097 & 62 & 12 & 12 \\
\hline Inferior frontal G & 47 & 1 (37792) & 0.0128 & -40 & 36 & -6 & 7 (2552) & 0.0091 & 46 & 24 & -8 \\
\hline Middle frontal G & 10 & 1 (37792) & 0.0095 & -42 & 48 & -12 & 7 (2552) & 0.0078 & 40 & 50 & 14 \\
\hline Middle frontal G & 10 & 20 (816) & 0.0089 & -34 & 50 & 14 & & & & & \\
\hline Middle frontal G & 46 & 1 (37792) & 0.0081 & -46 & 32 & 16 & $4(3832)$ & 0.0170 & 50 & 22 & 24 \\
\hline Middle frontal G & 9 & 1 (37792) & 0.0087 & -52 & 14 & 36 & & & & & \\
\hline Middle frontal G & 8 & 1 (37792) & 0.0124 & -32 & 24 & 44 & & & & & \\
\hline Medial frontal G & 6 & & & & & & 1 (37792) & 0.0223 & -6 & 22 & 42 \\
\hline Precentral G & 4 & 8 (3276) & 0.0088 & -36 & -18 & 56 & & & & & \\
\hline \multicolumn{12}{|l|}{ INSULA } \\
\hline Insula & 13 & 1 (37792) & 0.0204 & -42 & 20 & 4 & 7 (2552) & 0.0089 & 40 & 24 & -6 \\
\hline \multicolumn{12}{|l|}{ CINGULATE G } \\
\hline Cingulate G & 32 & 1 (37792) & 0.0231 & -8 & 28 & 30 & & & & & \\
\hline Cingulate G & 24 & 1 (37792) & 0.0089 & -2 & 18 & 30 & & & & & \\
\hline Cingulate G & 31 & $23(744)$ & 0.0121 & -4 & -46 & 32 & & & & & \\
\hline \multicolumn{12}{|l|}{ TEMPORAL LOBE } \\
\hline Superior temporal G & 38 & 1 (37792) & 0.0129 & -50 & 14 & -22 & & & & & \\
\hline Superior temporal G & 22 & $12(1432)$ & 0.0160 & -56 & -40 & 10 & $11(1520)$ & 0.0094 & 50 & -26 & 0 \\
\hline Precuneus & 19 & $3(3920)$ & 0.0152 & -30 & -64 & 44 & $18(864)$ & 0.0075 & 30 & -72 & 44 \\
\hline Supramarginal G & 40 & 5 (3248) & 0.0155 & -48 & -52 & 24 & & & & & \\
\hline Inferior parietal lobule & 40 & 8 (3276) & 0.0118 & -40 & -32 & 46 & & & & & \\
\hline Postcentral G & 3 & 8 (3276) & 0.0125 & -36 & -26 & 50 & & & & & \\
\hline Superior parietal lobule & 7 & & & & & & $18(864)$ & 0.0126 & 30 & -62 & 46 \\
\hline \multicolumn{12}{|l|}{ OCCIPITAL LOBE } \\
\hline Inferior occipital G & 18 & $6(2568)$ & 0.0079 & -28 & -94 & -12 & $2(4216)$ & 0.0139 & 32 & -92 & -4 \\
\hline Superior occipital G & 19 & $3(3920)$ & 0.0111 & -36 & -78 & 34 & & & & & \\
\hline \multicolumn{12}{|l|}{ SUB-CORTICAL } \\
\hline Thalamus & & $10(1600)$ & 0.0110 & -10 & -18 & 12 & & & & & \\
\hline Lentiform nucleus & & & & & & & $11(1520)$ & 0.0100 & 34 & -16 & 8 \\
\hline Putamen & & 14 (1296) & 0.0105 & -32 & -12 & 2 & & & & & \\
\hline Lateral globus pallidus & & 14 (1296) & 0.0087 & -24 & -6 & -10 & & & & & \\
\hline Medial globus pallidus & & 14 (1296) & 0.0082 & -16 & -2 & -10 & & & & & \\
\hline \multicolumn{12}{|l|}{ CEREBELLUM } \\
\hline Cerebellar tonsil & & & & & & & 13 (1376) & 0.0083 & 38 & -70 & -36 \\
\hline Declive & & $6(2568)$ & 0.0093 & -24 & -84 & -18 & 13 (1376) & 0.0141 & 36 & -66 & -24 \\
\hline Declive & & & & & & & $22(776)$ & 0.0121 & 8 & -74 & -22 \\
\hline
\end{tabular}


Table 6 | Continued

\begin{tabular}{|c|c|c|c|c|c|c|c|c|c|c|c|}
\hline Location & \multicolumn{6}{|c|}{ Left } & \multicolumn{5}{|c|}{ Right } \\
\hline Tuber & & 16 (1208) & 0.0113 & -46 & -66 & -28 & & & & & \\
\hline Inferior Semi-Lunar & & & & & & & 17 (1048) & 0.0104 & 30 & -76 & -42 \\
\hline Pyramis & & & & & & & 17 (1048) & 0.0084 & 30 & -86 & -34 \\
\hline
\end{tabular}

Columns number 3-7 represent data associated with the left hemisphere and 7-12 represent data associated with the right hemisphere. Abbreviations: BA, approximate Brodmann area; ALE, activation likelihood estimation; G, gyrus; $x, y, z$ coordinates, peak voxel in the Montreal Neurologic Institute (MNI) space.

\section{Table 7 | Locations of clusters with significant ALE values for non-verbal tasks.}

\begin{tabular}{|c|c|c|c|c|c|c|c|c|c|c|c|}
\hline Location & \multicolumn{6}{|c|}{ Left } & \multicolumn{5}{|c|}{ Right } \\
\hline \multicolumn{12}{|l|}{ FRONTAL LOBE } \\
\hline Superior frontal G & 6 & $1(12432)$ & 0.0068 & -26 & 6 & 66 & & & & & \\
\hline Superior frontal G & 6 & $2(4184)$ & 0.0075 & -2 & 20 & 56 & & & & & \\
\hline Middle frontal G & 9 & 15 (1136) & 0.0083 & -26 & 42 & 26 & & & & & \\
\hline Middle frontal G & 6 & $1(12432)$ & 0.0068 & -34 & 2 & 46 & $3(2432)$ & 0.0108 & 24 & -6 & 50 \\
\hline Inferior frontal G & 9 & $1(12432)$ & 0.0095 & -44 & 10 & 26 & & & & & \\
\hline Inferior frontal G & 47 & 5 (1984) & 0.0075 & -46 & 26 & -6 & $6(1688)$ & 0.0116 & 32 & 18 & -24 \\
\hline Medial frontal G & 10 & 9 (1536) & 0.0112 & -8 & 62 & 10 & & & & & \\
\hline \multicolumn{12}{|l|}{ CINGULATE CORTEX } \\
\hline Cingulate G & 24 & $1(12432)$ & 0.0072 & -18 & 0 & 48 & & & & & \\
\hline \multicolumn{12}{|l|}{ INSULA } \\
\hline Insula & 13 & 5 (1984) & 0.0082 & -44 & 14 & -2 & & & & & \\
\hline \multicolumn{12}{|l|}{ PARIETAL LOBE } \\
\hline Supramarginal G & 40 & $4(2152)$ & 0.0084 & -38 & -44 & 42 & & & & & \\
\hline Inferior parietal lobule & 40 & $4(2152)$ & 0.0090 & -48 & -36 & 44 & $11(1328)$ & 0.0086 & 40 & -42 & 44 \\
\hline Superior parietal lobule & 7 & & & & & & $17(992)$ & 0.0082 & 32 & -58 & 56 \\
\hline Precuneus & 7 & $22(760)$ & 0.0076 & -20 & -64 & 48 & & & & & \\
\hline \multicolumn{12}{|l|}{ OCCIPITAL LOBE } \\
\hline Superior occipital G & 19 & 16 (1048) & 0.0103 & -42 & -80 & 36 & & & & & \\
\hline Declive & & & & & & & $8(1600)$ & 0.0083 & 32 & -70 & -22 \\
\hline Culmen & & 12 (1224) & 0.0087 & -30 & -60 & -24 & 18 (928) & 0.0080 & 36 & -54 & -24 \\
\hline \multicolumn{12}{|l|}{ SUBCORTICAL } \\
\hline Thalamus & & 13 (1192) & 0.0131 & -16 & -30 & -4 & 19 (904) & 0.0084 & 24 & -28 & 2 \\
\hline
\end{tabular}

Columns number 3-7 represent data associated with the left hemisphere and 7-12 represent data associated with the right hemisphere. Abbreviations: BA, approximate Brodmann area; ALE, activation likelihood estimation; $G$, gyrus; $x, y, z$ coordinates, peak voxel in the Montreal Neurologic Institute (MNI) space. 
Table 8 | Locations of clusters with significant ALE values for the contrast of verbal vs. non-verbal tasks and the reverse contrast.

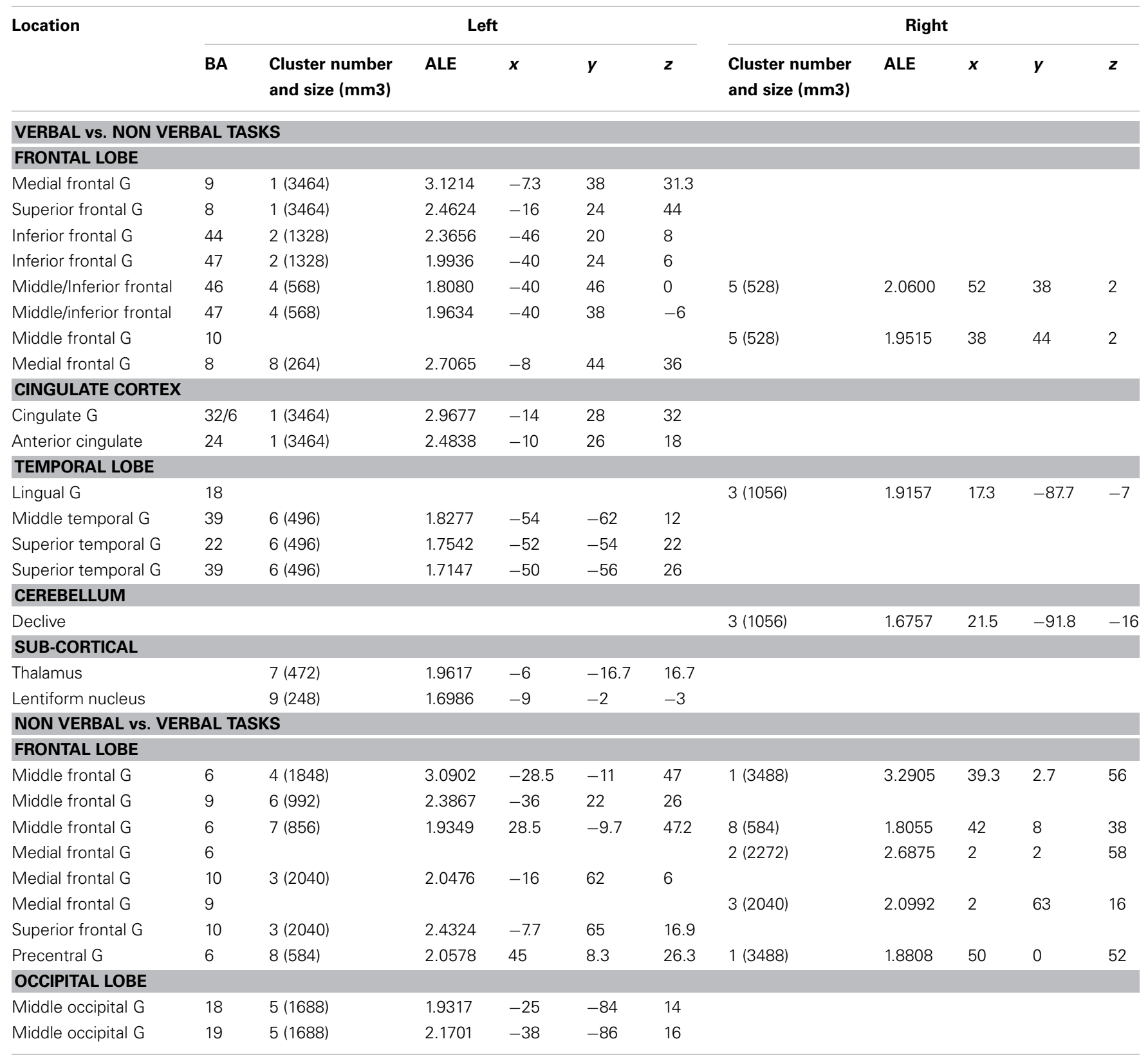

Columns number 3-7 represent data associated with the left hemisphere and 7-12 represent data associated with the right hemisphere. Abbreviations: BA, approximate Brodmann area; ALE, activation likelihood estimation; G, gyrus; $x, y, z$ coordinates, peak voxel in the Montreal Neurologic Institute (MNI) space.

2002; Smith et al., 2007), analogical reasoning, and similarity judgment (Wharton et al., 2000; Bunge et al., 2005; Geake and Hansen, 2005; Green et al., 2006; Wendelken et al., 2008; Crone et al., 2009; Garcin et al., 2012; Vartanian, 2012), abstract thinking (Badre, 2008; Christoff et al., 2009a, 2001) as well as coordinating goals and sub-goals (Koechlin et al., 1999; Koechlin and Hyafil, 2007). All of these functions may be involved in combination tasks. Therefore, the lateral rostral PFC could play a role in enabling subjects to find combinatorial solutions based on remote semantic associations or on relational similarity. This hypothesis is consistent with recent models that place the lateral rostral PFC at the top of a hierarchical organization of prefrontal functions according to progressively higher levels of abstraction (Christoff et al., 2001; Hampshire et al., 2010; Krawczyk et al., 2010), or to a greater distance from external stimuli when building internal thoughts (Christoff et al., 2003; Burgess et al., 2007). More posterior areas of the PFC are thought to be involved in the systematic control of representations necessary for these higher-level processes (Kroger et al., 2002; Brass et al., 2005; Cho et al., 2010; Wendelken and Bunge, 2010), and may be sufficient in some creativity tasks, such as free generation tasks. The rostral PFC is likely to operate as part of a network, together with other regions, such as the posterior STG and the temporo-parietal junction (BA 39), as suggested by the combination map and its contrast to the 
Table 9 | Summary table of the results and hypothetical roles of shared and task-oriented creativity regions.

\begin{tabular}{|c|c|}
\hline Regions & Hypothetical roles \\
\hline \multicolumn{2}{|c|}{ SHARED REGIONS: MAY REFLECT COGNITIVE CONTROL AND SEMANTIC MEMORY REQUIRED FOR IDEATION } \\
\hline left IFJ (BA44/6) extension to DLPFC & $\begin{array}{l}\text { Flexible cognitive control on information retrieved from memory and activation of task representations (Brass } \\
\text { et al., 2005) } \\
\text { In interaction with dorsal ACC (BA 32) (Beckmann et al., 2009) }\end{array}$ \\
\hline Left IFG (BA45/ 47) & $\begin{array}{l}\text { Controlled retrieval and/or selection of remote information from semantic memory (Martin and Cheng, 2006; } \\
\text { Thompson-Schill and Botvinick, 2006) } \\
\text { May control retrieval in connected parietal systems (BA 39) and allow higher levels of abstraction (Binder et al., } \\
\text { 2009) }\end{array}$ \\
\hline Left GA (BA 39) & $\begin{array}{l}\text { Concept retrieval from episodic and semantic memory, integration of different types of semantic information } \\
\text { (Binder et al., 2009; Bonner et al., 2013) }\end{array}$ \\
\hline \multicolumn{2}{|c|}{ COMBINATION ORIENTED: MAY BE INVOLVED IN RELATIONAL REASONING AND ABSTRACT THINKING } \\
\hline Left posterior MTG (BA 37/21) & $\begin{array}{l}\text { Storage, activation or retrieval of perceptual information about objects and their attributes, rules and concepts, } \\
\text { integration of their meaning (Binder et al., 2009; Price, 2010) }\end{array}$ \\
\hline Right IFG (BA 44/45) & $\begin{array}{l}\text { Suppression of inappropriate mindsets or responses (Aron et al., 2003; Volle et al., 2012) and switching to } \\
\text { alternatives } \\
\text { Lateral transformation of the problem (Goel and Vartanian, 2005) }\end{array}$ \\
\hline \multicolumn{2}{|c|}{ UNUSUAL GENERATION ORIENTED: MAY BE RELATED TO INCREASED WORKING MEMORY REOUIREMENTS } \\
\hline Left DLPFC (BA 45/46) & $\begin{array}{l}\text { Updating and manipulation of mindsets in working memory (verbal/semantic content) } \\
\text { Free selection of responses in working memory (Rowe et al., 2008) }\end{array}$ \\
\hline Left SMG (BA 40) & Maintenance on mindsets in working memory (Smith and Jonides, 1999) \\
\hline
\end{tabular}

* This region was found to be associated with unusual generation tasks, but was not significant when contrasting unusual generation with combination tasks.

generation map. Further clarification is needed to determine the respective role of each region in detecting similarities and combining different elements. Anatomically, these co-activations may be supported by direct connections between the PFC and superior lateral temporal areas, as shown in monkeys by Petrides and Pandya (2007).

A right-lateralized IFG activation was more prominent for combination than for unusual generation. This finding may be related to the fact that tasks classified in the combination category included insight problem-solving tasks, which have been shown to involve the right IFG in relation to shifts in hypothesis generation (Goel and Vartanian, 2005). The right IFG is also associated with suppression of inappropriate mindsets or responses (Aron et al., 2003; Volle et al., 2012), which may be more important in combination than in unusual generation tasks, in order to suppress unsuitable self-generated responses. Insight in problem solving has also been associated with the right temporal pole, a region closely connected with IFG through the uncinate fasciculus (Jung-Beeman et al., 2004; Bowden et al., 2005). That this result rather reflects a stronger interaction between the two hemispheres in order to combine ideas cannot be ruled out (Takeuchi et al., 2010b).

\section{Regions showing greater activity for unusual generation than combination tasks (Table 9)}

While combination tasks engaged the lateral rostral PFC, unusual generation maps showed the involvement of its medial part (Figure 2A). Although this rostromedial PFC region was not significant when contrasting unusual generation to combination maps (Figure 2B), this result is in agreement with a lesion study that showed that the medial rostral PFC region is critical for unusual generation performance (Alternate Uses tasks and TTCT) and, more specifically, that it is associated with the unusualness (originality) of the responses (Shamay-Tsoory et al., 2011). The role of the medial rostral PFC (BA 10) may not be limited to the evocation of unusual responses in generation tasks. Green et al. (2012) found more activation in this region when the domains compared in analogical reasoning were remote. Thus, semantic distance or information dissimilarity might be coded in this region. This may explain that activation in the rostromedial PFC was not statistically significant when comparing directly unusual generation to combination tasks (Figure 2B), since the semantic distance/dissimilarity factor may have an effect on both. It is noteworthy that the link between the medial rostral PFC and novelty/unusualness has been made outside the scope of creativity 
studies. For example, Krueger et al. (2007) showed scripts of real life events to subjects participating in an fMRI experiment and found that the medial rostral PFC was involved in coping with unusual situations more than with frequent ones. This region has also been associated with counterfactual thinking (Gomez Beldarrain et al., 2005; Van Hoeck et al., 2013), prospective memory and future thinking (Hassabis et al., 2007; Schacter et al., 2007; Abraham et al., 2008; Addis et al., 2009; Szpunar et al., 2009; Burgess et al., 2011; Volle et al., 2011), mentalizing (Frith and Frith, 2006; Andrews-Hanna et al., 2010; Gilbert et al., 2010), and daydreaming (Christoff et al., 2009b; Mason et al., 2007). These cognitive functions may be involved in the search for alternative responses in generation tasks. The relative role of medial vs. lateral rostral PFC in creative thinking will be an interesting question to address in future studies, in terms of representations or processes, and in the light of existing theories (Burgess et al., 2007; Buckner et al., 2008; Christoff et al., 2009b).

Unusual generation tasks, when compared statistically to combination tasks (Figure 2B), were associated with the dorsolateral prefrontal area (BA 9), the anterior inferior parietal region (left inferior parietal lobule and dorsal supramarginal gyrus, BA 40), and the cerebellar lobes (Figure 2B). This result is consistent with a previous finding from Chavez-Eakle et al. (2007) based on correlations between CBF and performance on TTCT. The supramarginal gyrus and middle frontal gyrus are anatomically connected (Catani and Thiebaut de Schotten, 2012). The involvement of this fronto-parietal network in generation tasks could be related to its role in working memory, monitoring, and/or attention- a set of functions more involved in generation than in combination tasks. The fronto-parietal regions have also been associated with the free and/or random generation of actions (Frith et al., 1991; Rowe et al., 2008) that requires the freedom of choice of one's responses as well as their selection and monitoring. Both are likely to participate in creative generation tasks that engage spontaneous willed actions. The role of the cerebellum in human cognition is poorly understood. A recent metaanalysis of functional imaging studies showed the involvement of the cerebellar lobes in six high-level functions: emotion, working memory, executive functions, music, timing, and language (E et al., 2012). All these domains may be involved in creativity tasks, and it is difficult to draw precise conclusions from the present study. Nevertheless, cerebellar lobes appeared to be more associated with verbal than non-verbal tasks in the present metaanalysis, which is in agreement with the particular involvement of lobule VI (Declive) in language reported by E et al. (2012).

\section{Verbal vs. non-verbal experiments}

The separated ALE analyses for verbal and non-verbal experiments (Figure 3A) and the statistical comparison between them (Figure 3B) showed that tasks using verbal material engage more inferior regions than those using non-verbal ones in the lateral prefrontal, occipital, and medial frontal regions. A ventral/dorsal dissociation according to verbal/non-verbal domain of information in the caudal part of the lateral PFC has often been reported (Goldman-Rakic, 1987; Mottaghy et al., 2002; Curtis and D'Esposito, 2003; Sakai and Passingham, 2003; Courtney, 2004; Mottaghy, 2006; Mohr et al., 2006; Postle, 2006; Sala and
Courtney, 2007; Volle et al., 2008). The analysis of non-verbal tasks showed bilateral activation in dorsal prefrontal areas (superior frontal gyrus), in regions implicated in attention, visuospatial processing, and working memory. Compared to verbal tasks, non-verbal tasks were also associated with more activation foci within the left rostral PFC, in the left occipital cortex, and in bilateral dorso-caudal prefrontal regions. However, because the non-verbal experiments gathered heterogeneous stimuli (visual, spatial, music), it is difficult to interpret these results and their apparent left dominance.

Finally, this second set of results supports the view that distinct creativity tasks could make different demands on cognitive processes that are subserved by different brain regions, in particular in rostral vs. caudal prefrontal areas. These regions, when damaged, may affect some aspects of creativity but each in a different manner.

\section{CONCLUSION}

The present findings highlighted the importance of caudal and rostral prefrontal regions, together with inferior parietal and posterior temporal areas, for the cognitive aspects of creativity. We further showed that some of these regions (mainly prefrontal ones) were shared by all task categories investigated, whereas other regions were more specifically associated with particular tasks. The core creativity network outlined by this meta-analysis is consistent with previous findings from different approaches in both healthy subjects and patients. Within this network, the lateral PFC (and especially the left IFJ) has been associated with various executive processes, such as fluency, flexibility, inhibition of prepotent responses, and cognitive control. These processes may represent components of creative thinking. In addition, this core network includes semantic regions, i.e., the left angular gyrus, STG and IFG, which have been related to the retrieval or connection of semantic associates. Retrieving and activating distant mental representations may constitute some of the mechanisms that allow creativity to emerge in both combination and free generation tasks. Subsequent task-dependent analyses revealed more specific regions in rostral PFC and in parietotemporal regions. Among them, the lateral rostral PFC and posterior temporal regions, associated with combination tasks, may more specifically support the ability to combine information in new ways, bridging semantic distances and/or superficial dissimilarities between them. A more caudal dorsolateral PFC region together with the inferior parietal lobule, associated with generation tasks, might rather support the free production of unusual or alternative responses. However, the cognitive processes involved in creativity are not yet understood, and their identification was outside the scope of this study. This meta-analysis does not enable us to determine whether or not the observed regions support processes specific to creative thinking. Further studies should explore whether and how original ideas emerge automatically from remote activation in semantic networks or whether they result from an effortful cognitive set of processes.

\section{ACKNOWLEDGMENTS}

This work was supported by the "Agence Nationale de la Recherche” [grant number ANR-09-RPDOC-004-01]. 


\section{REFERENCES}

Abraham, A., Beudt, S., Ott, D. V. M., and von Cramon, D. Y. (2012a). Creative cognition and the brain, Dissociations between frontal, parietal-temporal and basal ganglia groups. Brain Res. 1482, 55-70. doi: 10.1016/j.brainres.2012. 09.007

Abraham, A., Pieritz, K., Thybusch, K., Rutter, B., Kröger, S., Schweckendiek, J., et al. (2012b). Creativity and the brain: uncovering the neural signature of conceptual expansion. Neuropsychologia 50, 1906-1917. doi: 10.1016/j. neuropsychologia.2012.04.015

Abraham, A., Schubotz, R. I., and von Cramon, D. Y. (2008). Thinking about the future versus the past in personal and non-personal contexts. Brain Res. 1233, 106-119. doi: 10.1016/j.brainres.2008.07.084

Addis, D. R., Pan, L., Vu, M.-A., Laiser, N., and Schacter, D. L. (2009). Constructive episodic simulation of the future and the past, Distinct subsystems of a core brain network mediate imagining and remembering. Neuropsychologia 47, 2222-2238. doi: 10.1016/j. neuropsychologia.2008.10.026

Andrews-Hanna, J. R., Reidler, J. S., Huang, C., and Buckner, R. L. (2010). Evidence for the default network's role in spontaneous cognition. J. Neurophysiol. 104, 322-335. doi: 10.1152/jn.00830. 2009

Arden, R., Chavez, R. S., Grazioplene, R., and Jung, R. E. (2010). Neuroimaging creativity, A psychometric view. Behav. Brain Res. 214, 143-156. doi: 10.1016/j.bbr.2010. 05.015

Aron, A. R., Fletcher, P. C., Bullmore, E. T., Sahakian, B. J., and Robbins, T. W. (2003). Stop-signal inhibition disrupted by damage to right inferior frontal gyrus in humans. Nat. Neurosci. 6, 115-116. doi: 10.1038/nn 1003

Asari, T., Konishi, S., Jimura, K., Chikazoe, J., Nakamura, N., and Miyashita, Y. (2008). Right temporopolar activation associated with unique perception. Neuroimage 41, 145-152. doi: 10.1016/j.neuroimage.2008.01.059

Aziz-Zadeh, L., Kaplan, J. T., and Iacoboni, M. (2009). «Aha! 》: the neural correlates of verbal insight solutions. Hum. Brain Mapp. 30, 908-916. doi: 10.1002/hbm.20554

Aziz-Zadeh, L., Liew, S.-L., and Dandekar, F. (2013). Exploring the neural correlates of visual creativity. Soc. Cogn. Affect. Neurosci. 8, 475-480. doi: 10.1093/scan/nss021
Azuar, C., Reyes, P., Slachevsky, A., Kinkingnehun, S., Kouneiher, F., Volle, E., et al. (2010). "Lesion behavior mapping in patients with lateral frontal lesions and cognitive control impairments,"in Frontal Human Neuroscience Conference Abstract, The 20th Annual Rotman Research Institute Conference, The Frontal Lobes (Toronto, ON).

Badre, D. (2008). Cognitive control, hierarchy, and the rostro-caudal organization of the frontal lobes. Trends Cogn. Sci. 12, 193-200. doi: 10.1016/j.tics.2008.02.004

Badre, D., and Wagner, A. D. (2004). Selection, integration, and conflict monitoring; assessing the nature and generality of prefrontal cognitive control mechanisms. Neuron 41, 473-487. doi: 10.1016/S08966273(03)00851-1

Badre, D., and Wagner, A. D. (2007). Left ventrolateral prefrontal cortex and the cognitive control of memory. Neuropsychologia 45, 2883-2901. doi: 10.1016/ j.neuropsychologia.2007.06.015

Bates, E., Wilson, S. M., Saygin, A. P., Dick, F., Sereno, M. I., Knight, R. T., et al. (2003). Voxel-based lesionsymptom mapping. Nat. Neurosci. 6, 448-450.

Bechtereva, N. P., Korotkov, A. D., Pakhomov, S. V., Roudas, M. S., Starchenko, M. G., and Medvedev, S. V. (2004). PET study of brain maintenance of verbal creative activity. Int. J. Psychophysiol. 53, 11-20. doi: 10.1016/j.ijpsycho.2004.01.001

Beckmann, M., Johansen-Berg, H., and Rushworth, M. F. (2009). Connectivity-based parcellation of human cingulate cortex and its relation to functional specialization. J. Neurosci. 29, 1175-1190. doi: 10.1523/JNEUROSCI.3328-08.2009

Bengtsson, S. L., Csikszentmihalyi, M., and Ullen, F. (2007). Cortical regions involved in the generation of musical structures during improvisation in pianists. J. Cogn. Neurosci. 19, 830-842. doi: 10.1162/jocn.2007.19.5.830

Berkowitz, A. L., and Ansari, D. (2008). Generation of novel motor sequences: the neural correlates of musical improvisation. Neuroimage 41, 535-543. doi: 10.1016/j.neuroimage.2008.02.028

Binder, J. R., Desai, R. H., Graves, W. W., and Conant, L. L. (2009). Where is the semantic system? A critical review and meta-analysis of 120 functional neuroimaging studies. Cereb. Cortex 19, 2767-2796. doi: 10.1093/cercor/ bhp055
Bogousslavsky, J. (2005). Artistic creativity, style and brain disorders. Eur. Neurol. 54, 103-111. doi: 10.1159/000088645

Bonner, M. F., Peelle, J. E., Cook, P. A., and Grossman, M. (2013). Heteromodal conceptual processing in the angular gyrus. Neuroimage 71, 175-186. doi: 10.1016/j.neuroimage.2013.01.006

Bowden, E. M., and Jung-Beeman, M. (2003). Aha! Insight experience correlates with solution activation in the right hemisphere. Psychon. Bull. Rev. 10, 730-737. doi: 10.3758/BF03196539

Bowden, E. M., Jung-Beeman, M., Fleck, J., and Kounios, J. (2005). New approaches to demystifying insight. Trends Cogn. Sci. 9, 322-328. doi: 10.1016/j.tics.2005.05.012

Brass, M., Derrfuss, J., Forstmann, B., and Cramon, D. Y. (2005) The role of the inferior frontal junction area in cognitive control. Trends Cogn. Sci. 9, 314-316. doi: 10.1016/j.tics.2005.05.001

Buckner, R. L., Andrews-Hanna, J. R., and Schacter, D. L. (2008). The brain's default network, anatomy, function, and relevance to disease. Ann. N.Y. Acad. Sci. 1124, 1-38. doi: 10.1196/annals.1440.011

Bunge, S. A., Wendelken, C., Badre, D., and Wagner, A. D. (2005). Analogical reasoning and prefrontal cortex, evidence for separable retrieval and integration mechanisms. Cereb. Cortex 15, 239-249. doi: 10.1093/cercor/bhh126

Burgess, P. W., Dumontheil, I. I., and Gilbert, S. J. (2007). The gateway hypothesis of rostral prefrontal cortex (area 10) function. Trends Cogn. Sci. 11, 290-298. doi: 10.1016/j.tics.2007.05.004

Burgess, P. W., Gonen-Yaacovi, G. and Volle, E. (2011). Functional neuroimaging studies of prospective memory, what have we learnt so far? Neuropsychologia 49, 2246-2257. doi: 10.1016/ j.neuropsychologia.2011.02.014

Burgess, P. W., and Shallice, T. (1997). The Hayling and Brixton Tests. Bury St. Edmunds: Thames Valley Test Company.

Cardillo, E. R., Watson, C. E., Schmidt G. L., Kranjec, A., and Chatterjee, A. (2012). From novel to familiar: tuning the brain for metaphors. Neuroimage 59, 3212-3221. doi: 10.1016/j.neuroimage.2011.11.079

Carlsson, I., Wendt, P. E., and Risberg, J. (2000). On the neurobiology of creativity. Differences in frontal activity between high and low creative subjects. Neuropsychologia 38,
873-885. doi: 10.1016/S0028-3932 (99)00128-1

Catani, M., and Thiebaut de Schotten, M. (2012). Atlas of Human Brain Connections. Oxford: Oxford University Press. doi: 10.1093/ med/9780199541164.001.0001

Cerruti, C., and Schlaug, G. (2009). Anodal transcranial direct current stimulation of the prefrontal cortex enhances complex verbal associative thought. J. Cogn. Neurosci. 21, 1980-1987. doi: 10.1162/jocn.2008.21143

Changeux, J. (2005). "Creation, art, and brain," in Neurobiology of Human Values, eds J. P. Changeux, A. Damasio, and W. Singer (Berlin; Heidelberg: Springer-Verlan), 1-10. doi: 10.1007/3-540-29803-7_1

Chavez-Eakle, R. A., Graff-Guerrero, A., Garcia-Reyna, J. C., Vaugier, V., and Cruz-Fuentes, C. (2007). Cerebral blood flow associated with creative performance, a comparative study. Neuroimage 38, 519-528. doi: 10.1016/j.neuroimage.2007.07.059

Chi, R. P., and Snyder, A. W. (2011). Facilitate insight by non-invasive brain stimulation. PLoS ONE 6:e16655. doi: 10.1371/journal.pone.0016655

Chi, R. P., and Snyder, A. W. (2012). Brain stimulation enables the solution of an inherently difficult problem. Neurosci. Lett. 515, 121-124. doi: 10.1016/j.neulet.2012.03.012

Cho, S., Moody, T. D., Fernandino, L., Mumford, J. A., Poldrack, R. A., Cannon, T. D., et al. (2010). Common and dissociable prefrontal Loci associated with component mechanisms of analogical reasoning. Cereb. Cortex 20, 524-533. doi: 10.1093/cercor/bhp121

Christoff, K., Keramatian, K., Gordon, A. M., Smith, R., and Madler, B. (2009a). Prefrontal organization of cognitive control according to levels of abstraction. Brain Res. 1286, 94-105. doi: 10.1016/j.brainres.2009.05.096

Christoff, K., Gordon, A. M., Smallwood, J., Smith, R., and Schooler, J. W. (2009b). Experience sampling during fMRI reveals default network and executive system contributions to mind wandering. Proc. Natl. Acad. Sci. U.S.A. 106, 8719-8724. doi: 10.1073/pnas.0900234106

Christoff, K., Prabhakaran, V. Dorfman, J., Zhao, Z., Kroger, J. K., Holyoak, K. J., et al. (2001). Rostrolateral prefrontal cortex involvement in relational integration during reasoning. Neuroimage 14, 1136-1149. doi: 10.1006/nimg.2001.0922 
Christoff, K., Ream, J. M., Geddes, L. P., and Gabrieli, J. D. (2003). Evaluating self-generated information, anterior prefrontal contributions to human cognition. Behav. Neurosci. 117, 1161-1168. doi: $\quad 10.1037 / 0735-7044.117 .6$. 1161

Chrysikou, E. G., and ThompsonSchill, S. L. (2011). Dissociable brain states linked to common and creative object use. Hum. Brain Mapp. 32, 665-675. doi: 10.1002/hbm.21056

Courtney, S. M. (2004). Attention and cognitive control as emergent properties of information representation in working memory. Cogn. Affect. Behav. Neurosci. 4, 501-516. doi: 10.3758/CABN.4.4.501

Crone, E. A., Wendelken, C., van Leijenhorst, L., Honomichl, R. D., Christoff, K., and Bunge, S. A. (2009). Neurocognitive development of relational reasoning. Dev. Sci. 12, 55-66. doi: 10.1111/j.1467-7687.2008.00743.x

Curtis, C. E., and D'Esposito, M. (2003). Persistent activity in the prefrontal cortex during working memory. Trends Cogn. Sci. 7, 415-423. doi: $\quad 10.1016 /$ S1364-6613(03) 00197-9

de Manzano, Ö., and Ullén, F. (2012). Goal-independent mechanisms for free response generation: creative and pseudo-random performance share neural substrates. Neuroimage 59, 772-780. doi: 10.1016/j. neuroimage.2011.07.016

de Souza, L. C., Volle, E., Bertoux, M., Czernecki, V., Funkiewiez, A., Allali, G., et al. (2010). Poor creativity in frontotemporal dementia, a window into the neural bases of the creative mind. Neuropsychologia 48, 3733-3742. doi: 10.1016/j. neuropsychologia.2010.09.010

Derrfuss, J., Brass, M., Neumann, J., and von Cramon, D. Y. (2005). Involvement of the inferior frontal junction in cognitive control, meta-analyses of switching and Stroop studies. Hum. Brain Mapp. 25, 22-34. doi: $10.1002 / \mathrm{hbm}$. 20127

Dietrich, A. (2004). The cognitive neuroscience of creativity. Psychon. Bull. Rev. 11, 1011-1026. doi: 10.3758/BF03196731

Dietrich, A., and Kanso, R. (2010). A review of EEG, ERP, and neuroimaging studies of creativity and insight. Psychol. Bull. 136, 822-848. doi: 10.1037/ a0019749

Duncan, J., and Owen, A. M. (2000). Common regions of the human frontal lobe recruited by diverse cognitive demands. Trends Neurosci. 23, 475-483. doi: 10.1016/S01662236(00)01633-7

E, K. H., Chen, S.-H., Ringo, A., Ho, M.-H., and Desmond, J. E. (2012). A meta-analysis of cerebellar contributions to higher cognition from PET and fMRI studies. Hum. Brain Mapp. doi: 10.1002/ hbm.22194. [Epub ahead of print].

Eickhoff, S. B., Bzdok, D., Laird, A. R., Kurth, F., and Fox, P. T. (2012). Activation likelihood estimation meta-analysis revisited. Neuroimage 59, 2349-2361. doi: 10.1016/j.neuroimage.2011.09.017

Eickhoff, S. B., Laird, A. R., Grefkes, C., Wang, L. E., Zilles, K., and Fox, P. T. (2009). Coordinate-based activation likelihood estimation meta-analysis of neuroimaging data, a random-effects approach based on empirical estimates of spatial uncertainty. Hum. Brain Mapp. 30, 2907-2926. doi: 10.1002/hbm.20718

Ellamil, M., Dobson, C., Beeman, M., and Christoff, K. (2012). Evaluative and generative modes of thought during the creative process. Neuroimage 59, 1783-1794. doi: 10.1016/j.neuroimage.2011.08.008

Evans, A. C., Collins, D. L., Mills, S. R., Brown, R. D., Kelly, R. L., and Peters, T. M. (1993). 3D statistical neuroanatomical models from 305 MRI volumes. IEEE Nucl. Sci. Symp. Med. Imag. 108, 1877-1878.

Fink, A., and Benedek, M. (2013). EEG alpha power and creative ideation. Neurosci. Biobehav. Rev. doi: $\quad$ 10.1016/j.neubiorev.2012. 12.002. [Epub ahead of print]

Fink, A., Benedek, M., Grabner, R. H., Staudt, B., and Neubauer, A. C. (2007). Creativity meets neuroscience, experimental tasks for the neuroscientific study of creative thinking. Methods 42, 68-76. doi: 10.1016/j.ymeth.2006.12.001

Fink, A., Grabner, R. H., Benedek, M., Reishofer, G., Hauswirth, V., Fally, M., et al. (2009). The creative brain: investigation of brain activity during creative problem solving by means of EEG and FMRI. Hum. Brain Mapp. 30, 734-748. doi: 10.1002/hbm.20538

Fink, A., Grabner, R. H., Gebauer, D., Reishofer, G., Koschutnig, K., and Ebner, F. (2010). Enhancing creativity by means of cognitive stimulation: evidence from an fMRI study. Neuroimage 52, 1687-1695. doi: 10.1016/j.neuroimage.2010.05.072

Friedman, R. S., and Forster, J. (2005). Effects of motivational cues on perceptual asymmetry, implications for creativity and analytical problem solving. J. Pers. Soc. Psychol. 88, 263-275. doi: 10.1037/00223514.88.2.263

Frith, C. D. (2000). "The role of the dorsolateral prefrontal cortex in the selection of action as revealed by functional imaging," in Control of Cognitive Processes, Attention and Performance XVIII, eds S. Monsell and J. Driver (Cambridge, MA: MIT Press), 549-565.

Frith, C. D., Friston, K., Liddle, P. F. and Frackowiak, R. S. (1991). Willed action and the prefrontal cortex in man: a study with PET. Proc. R. Soc. Lond. B Biol. Sci. 44, 241-246. doi 10.1098/rspb.1991.0077

Frith, C. D., and Frith, U. (2006) The neural basis of mentalizing. Neuron 50, 531-534. doi: 10.1016/j.neuron.2006.05.001

Garavan, H., Ross, T. J., and Stein, E. A. (1999). Right hemispheric dominance of inhibitory control, an event-related functional MRI study. Proc. Natl. Acad. Sci. U.S.A. 96, 8301-8306. doi 10.1073/pnas.96.14.8301

Garcin, B., Volle, E., Dubois, B., and Levy, R. (2012). Similar or different? The role of the ventrolateral prefrontal cortex in similarity detection. PLoS ONE 7:e34164. doi: 10.1371/journal.pone.0034164

Geake, J. G., and Hansen, P. C. (2005). Neural correlates of intelligence as revealed by fMRI of fluid analogies. Neuroimage 26, 555-564. doi: 10.1016/j.neuroimage.2005 01.035

Gilbert, S. J., Gonen-Yaacovi, G. Benoit, R. G., Volle, E., and Burgess, P. W. (2010). Distinct functional connectivity associated with lateral versus medial rostral prefrontal cortex, a meta-analysis. Neuroimage 53, 1359-1367. doi: 10.1016/j.neuroimage.2010.07.032

Goel, V., and Grafman, J. (2000) Role of the right prefrontal cortex in ill-structured planning. $\operatorname{Cog}$. Neuropsychol. 17, 415-436. doi 10.1080/026432900410775

Goel, V., and Vartanian, O. (2005) Dissociating the roles of right ventral lateral and dorsal lateral prefrontal cortex in generation and maintenance of hypotheses in set-shift problems. Cereb. Cortex 15, 1170-1177. doi 10.1093/cercor/bhh217

Goldman-Rakic, P. S. (1987). Circuitry of the frontal association cortex and its relevance to dementia. Arch. Gerontol. Geriatr. 6, 299-309. doi: 10.1016/0167-4943(87)90029-X

Gomez Beldarrain, M., Garcia-Monco, J. C., Astigarraga, E., Gonzalez,
A., and Grafman, J. (2005). Only spontaneous counterfactual thinking is impaired in patients with prefrontal cortex lesions. Brain Res. Cogn. Brain Res. 24, 723-726. doi: 10.1016/j.cogbrainres.2005.03.013

Green, A. E., Fugelsang, J. A., Kraemer, D. J., Shamosh, N. A., and Dunbar, K. N. (2006). Frontopolar cortex mediates abstract integration in analogy. Brain Res. 1096, 125-137. doi: 10.1016/j.brainres.2006.04.024

Green, A. E., Kraemer, D. J. M., Fugelsang, J. A., Gray, J. R., and Dunbar, K. N. (2012). Neural correlates of creativity in analogical reasoning. J. Exp. Psychol. Learn. Mem. Cogn. 38, 264-272. doi: 10.1037/a0025764

Guilford, J. P. (1950). Creativity. Am. Psychol. 5, 444-454. doi: 10.1037/h0063487

Hampshire, A., Chamberlain, S. R., Monti, M. M., Duncan, J., and Owen, A. M. (2010). The role of the right inferior frontal gyrus, inhibition and attentional control. Neuroimage 50, 1313-1319. doi: 10.1016/j.neuroimage.2009.12.109

Hassabis, D., Kumaran, D., and Maguire, E. A. (2007). Using imagination to understand the neural basis of episodic memory. J. Neurosci. 27, 14365-14374. doi: 10.1523/JNEUROSCI.4549-07.2007

Hillis, A. E., Chang, S., Breese, E. and Heidler, J. (2004). The crucial role of posterior frontal regions in modality specific components of the spelling process. Neurocase 10, 175-187.

Holmes, C. J., Hoge, R., Collins, L., Woods, R., Toga, A. W., and Evans, A. C. (1998). Enhancement of MR images using registration for signal averaging. J. Comput. Assist. Tomogr. 22, 324-333. doi: 10.1097/00004728-19980300000032

Howard-Jones, P. A., Blakemore, S. J., Samuel, E. A., Summers, I. R., and Claxton, G. (2005). Semantic divergence and creative story generation, an fMRI investigation. Brain Res. Cogn. Brain Res. 25, 240-250. doi: 10.1016/j.cogbrainres.2005.05.013

Huang, P., Qiu, L., Shen, L., Zhang, Y., Song, Z., Qi, Z., et al. (2012). Evidence for a left-over-right inhibitory mechanism during figural creative thinking in healthy nonartists. Hum. Brain Mapp. doi 10.1002/hbm.22093. [Epub ahead of print]

Jung, R. E., Grazioplene, R., Caprihan, A., Chavez, R. S., and Haier, R. J. (2010a). White matter integrity, creativity, and psychopathology, disentangling constructs with diffusion 
tensor imaging. PLoS ONE 5:e9818. doi: 10.1371/journal.pone.0009818

Jung, R. E., Segall, J. M., Bockholt, H. J., Flores, R. A., Smith, S. M., Chavez, R. S., et al. (2010b). Neuroanatomy of creativity. Hum. Brain Mapp. 31, 398-409. doi: 10.1002/hbm.20874

Jung, R. E., and Haier, R. J. (2007). The Parieto-Frontal Integration Theory (P-FIT) of intelligence: converging neuroimaging evidence. Behav. Brain Sci. 30, 135-154. discussion: 154-187. doi: 10.1017/ S0140525X07001185

Jung-Beeman, M., Bowden, E. M., Haberman, J., Frymiare, J. L., Arambel-Liu, S., Greenblatt, R., et al. (2004). Neural activity when people solve verbal problems with insight. PLoS Biol. 2:e97. doi: 10.1371/journal.pbio.0020097

Kan, I. P., and Thompson-Schill, S. L. (2004). Selection from perceptual and conceptual representations. Cogn. Affect. Behav. Neurosci. 4, 466-482. doi: 10.3758/CABN.4. 4.466

Kenner, N. M., Mumford, J. A., Hommer, R. E., Skup, M., Leibenluft, E., and Poldrack, R. A. (2010). Inhibitory motor control in response stopping and response switching. J. Neurosci. 30, 8512-8518. doi: 10.1523/ JNEUROSCI.1096-10.2010

Kim, C., Johnson, N. F., Cilles, S. E., Gold, B. T. (2011). Common and distinct mechanisms of cognitive flexibility in prefrontal cortex. J. Neurosci. 31, 4771-4779. doi: 10.1523/JNEUROSCI.5923-10.2011

Kinkingnehun, S., Volle, E., PelegriniIssac, M., Golmard, J. L., Lehericy, S., du Boisgueheneuc, F., et al. (2007). A novel approach to clinical-radiological correlations, Anatomo-Clinical Overlapping Maps (AnaCOM), method and validation. Neuroimage 37, 1237-1249. doi: $\quad 10.1016 /$ j.neuroimage.2007. 06.027

Knoblich, G., Ohlsson, S., Haider, H., and Rhenius, D. (1999). Constraint relaxation and chunk decomposition in insight problem solving. J. Exp. Psychol. Learn. Mem. Cogn. 25, 1534-1555. doi: 10.1037/02787393.25.6.1534

Koechlin, E., Basso, G., Pietrini, P., Panzer, S., and Grafman, J. (1999). The role of the anterior prefrontal cortex in human cognition. Nature 399, 148-151. doi: 10.1038/ 20178

Koechlin, E., and Hyafil, A. (2007). Anterior prefrontal function and the limits of human decisionmaking. Science 318, 594-598. doi: 10.1126/science.1142995
Koechlin, E., Ody, C., and Kouneiher, F. (2003). The architecture of cognitive control in the human prefrontal cortex. Science 302, 1181-1185. doi: 10.1126/science. 1088545

Konishi, S., Nakajima, K., Uchida, I., Kikyo, H., Kameyama, M., and Miyashita, Y. (1999). Common inhibitory mechanism in human inferior prefrontal cortex revealed by event-related functional MRI. Brain 122, 981-991. doi: 10.1093/brain/122.5.981

Kounios, J., Frymiare, J. L., Bowden, E. M., Fleck, J. I., Subramaniam, K., Parrish, T. B., et al. (2006). The prepared mind: neural activity prior to problem presentation predicts subsequent solution by sudden insight. Psychol. Sci. 17, 882-890. doi: $10.1111 /$ j.1467-9280. 2006.01798.x

Kowatari, Y., Lee, S. H., Yamamura, H., Nagamori, Y., Levy, P., Yamane, S., et al. (2009). Neural networks involved in artistic creativity. Hum. Brain Mapp. 30, 1678-1690. doi: 10.1002/hbm.20633

Krainik, A., Lehericy, S., Duffau, H., Capelle, L., Chainay, H., Cornu, P., et al. (2003). Postoperative speech disorder after medial frontal surgery, role of the supplementary motor area. Neurology 60, 587-594 doi: 10.1212/01.WNL.0000048206. 07837.59

Krawczyk, D. C., McClelland, M. M., Donovan, C. M., Tillman, G. D., and Maguire, M. J. (2010). An fMRI investigation of cognitive stages in reasoning by analogy. Brain Res. 1342, 63-73. doi: 10.1016/j.brainres.2010.04.039

Kroger, J. K., Sabb, F. W., Fales, C. L., Bookheimer, S. Y., Cohen, M. S., and Holyoak, K. J. (2002). Recruitment of anterior dorsolateral prefrontal cortex in human reasoning, a parametric study of relational complexity. Cereb. Cortex 12,477-485. doi: 10.1093/cercor/12. 5.477

Kröger, S., Rutter, B., Stark, R. Windmann, S., Hermann, C., and Abraham, A. (2012). Using a shoe as a plant pot: neural correlates of passive conceptual expansion. Brain Res. 1430, 52-61. doi: 10.1016/j.brainres.2011.10.031

Krueger, F., Moll, J., Zahn, R., Heinecke, A., and Grafman, J. (2007). Event frequency modulates the processing of daily life activities in human medial prefrontal cortex. Cereb. Cortex 17, 2346-2353. doi: 10.1093/ cercor/bhl143

Laird, A. R., Fox, P. M., Price, C. J., Glahn, D. C., Uecker, A. M., Lancaster, J. L., et al. (2005). ALE meta-analysis, controlling the false discovery rate and performing statistical contrasts. Hum Brain Mapp. 25, 155-164. doi: 10.1002/hbm.20136

Liddle, P. F., Kiehl, K. A., and Smith, A. M. (2001). Event-related fMRI study of response inhibition. Hum. Brain Mapp. 12, 100-109.

Limb, C. J., and Braun, A. R. (2008). Neural substrates of spontaneous musical performance: an fMRI study of jazz improvisation. PLOS ONE 3:e1679. doi 10.1371/journal.pone.0001679

Lubart, T. (2003). Psychologie de la créativité. Paris: Armand Colin.

Luo, J., Niki, K., and Phillips, S. (2004). Neural correlates of the «Aha! reaction 》. Neuroreport 15 2013-2017. doi: 10.1097/00001756200409150-00004

Martin, R. C., and Cheng, Y. (2006). Selection demands versus association strength in the verb generation task. Psychon. Bull. Rev. 13 396-401. doi: 10.3758/BF03193859

Mashal, N., Faust, M., Hendler, T., and Jung-Beeman, M. (2007). An fMRI investigation of the neural correlates underlying the processing of nove metaphoric expressions. Brain Lang. 100, 115-126. doi: 10.1016/j.bandl. 2005.10.005

Mason, M. F., Norton, M. I., Van Horn, J. D., Wegner, D. M., Grafton, S. T., and Macrae, C. N. (2007) Wandering minds, the default network and stimulus-independent thought. Science 315, 393-395. doi 10.1126/science. 1131295

Mednick, M. T., Mednick, S. A., and Jung, C. C. (1964a). Continual association as a function of level of creativity and type of verbal stimulus. J. Abnorm. Psychol. 69, 511-515. doi: 10.1037/h0041086

Mednick, M. T., Mednick, S. A., and Mednick, E. V. (1964b) Incubation of creative performance and specific associative priming. J. Abnorm. Psychol. 69, 84-88. doi 10.1037/h0045994

Mednick, S. A. (1962). The associative basis of the creative process. Psychol. Rev. 69, 220-232. doi: $10.1037 / \mathrm{h} 0048850$

Mendez, M. F. (2004). Dementia as a window to the neurology of art. Med. Hypotheses 63, 1-7. doi: 10.1016/j.mehy.2004.03.002

Menon, V., Adleman, N. E., White, C. D., Glover, G. H., and Reiss, A. L (2001). Error-related brain activation during a Go/NoGo response inhibition task. Hum. Brain Mapp. 12, 131-143.

Metuki, N., Sela, T., and Lavidor, M. (2012). Enhancing cognitive control components of insight problems solving by anodal tDCS of the left dorsolateral prefrontal cortex. Brain Stimul. 5, 110-115. doi: 10.1016/j. brs.2012.03.002

Miller, L. A., and Tippett, L. J. (1996). Effects of focal brain lesions on visual problem-solving. Neuropsychologia 34, 387-398. doi: 10.1016/0028-3932(95)00116-6

Mohr, H. M., Goebel, R., and Linden, D. E. (2006). Contentand task-specific dissociations of frontal activity during maintenance and manipulation in visual working memory. J. Neurosci. 26, 4465-4471. doi: 10.1523/JNEUROSCI.5232-05.2006

Mottaghy, F. M. (2006). Interfering with working memory in humans. Neuroscience 139, 85-90. doi: 10.1016/j.neuroscience.2005.05.037

Mottaghy, F. M., Gangitano, M. Sparing, R., Krause, B. J., and Pascual-Leone, A. (2002). Segregation of areas related to visual working memory in the prefrontal cortex revealed by rTMS. Cereb. Cortex 12, 369-375. doi: 10.1093/cercor/12.4.369

Munakata, Y., Herd, S. A., Chatham, C. H., Depue, B. E., Banich, M. T. and O'Reilly, R. C. (2011). A unified framework for inhibitory control. Trends Cogn. Sci. 15, 453-459. doi: 10.1016/j.tics.2011.07.011

Nathaniel-James, D. A., and Frith, C. D. (2002). The role of the dorsolateral prefrontal cortex, evidence from the effects of contextual constraint in a sentence completion task. Neuroimage 16, 1094-1102. doi: 10.1006/nimg.2002.1167

Perret, E. (1974). The left frontal lobe of man and the suppression of habitual responses in verbal categorical behaviour. Neuropsychologia 12, 323-330. doi: 10.1016/00283932(74)90047-5

Petrides, M., and Pandya, D. N. (2007). Efferent association pathways from the rostral prefrontal cortex in the macaque monkey. J. Neurosci. 27, 11573-11586. doi 10.1523/JNEUROSCI.2419-07.2007

Picton, T. W., Stuss, D. T., Alexander, M. P., Shallice, T., Binns, M. A., and Gillingham, S. (2007). Effects of focal frontal lesions on response inhibition. Cereb. Cortex 17, 826-838. doi: 10.1093/cercor/bhk031

Plucker, J. A., and Makel, M. C. (2010) "Assessment of Creativity," in The Cambridge Handbook of Creativity, eds J. Kaufman and R. Sternberg New York, NY: Cambridge University Press), 48-73. doi: 10.1017/CBO9780511763205.005 
Postle, B. R. (2006). Working memory as an emergent property of the mind and brain. Neuroscience 139, 23-38. doi: 10.1016/j.neuroscience.2005.06.005

Price, C. J. (2010). The anatomy of language: a review of 100 fMRI studies published in 2009. Ann. N. Y. Acad. Sci. 1191, 62-88. doi: $10.1111 / j .1749-6632.2010 .05444 . x$

Qiu, J., Li, H., Jou, J., Liu, J., Luo, Y., Feng, T., et al. (2010). Neural correlates of the « Aha $\gg$ experiences: evidence from an fMRI study of insight problem solving. Cortex 46, 397-403. doi: 10.1016/j.cortex.2009.06.006

Reverberi, C., Toraldo, A., D'Agostini, S., and Skrap, M. (2005). Better without (lateral) frontal cortex? Insight problems solved by frontal patients. Brain 128, 2882-2890. doi: 10.1093/brain/awh577

Rieger, M., Gauggel, S., and Burmeister, K. (2003). Inhibition of ongoing responses following frontal, nonfrontal, and basal ganglia lesions. Neuropsychology 17, 272-282. doi: 10.1037/0894-4105.17.2.272

Rowe, J., Hughes, L., Eckstein, D., and Owen, A. M. (2008). Ruleselection and action-selection have a shared neuroanatomical basis in the human prefrontal and parietal cortex. Cereb. Cortex 18, 2275-2285. doi: 10.1093/cercor/ bhm 249

Runco, M. A. (2010). "Divergent Thinking, Creativity, and Ideation," in The Cambridge Handbook of Creativity, eds J. Kaufman and R. Sternberg (New York, NY: Cambridge University Press), 413-446. doi: 10.1017/СBO9780511763205.026

Runco, M. A., and Jaeger, G. J. (2012). The standard definition of creativity. Creat. Res. J. 24, 92-96. doi: 10.1080/10400419.2012.650092

Rutter, B., Kröger, S., Stark, R., Schweckendiek, J., Windmann, S., Hermann, C., et al. (2012). Can clouds dance? Neural correlates of passive conceptual expansion using a metaphor processing task: implications for creative cognition. Brain Cogn. 78, 114-122. doi: 10.1016/j.bandc.2011.11.002

Sakai, K., and Passingham, R. E. (2003). Prefrontal interactions reflect future task operations. Nat. Neurosci. 6, 75-81. doi: 10.1038/nn987

Sala, J. B., and Courtney, S. M. (2007). Binding of what and where during working memory maintenance. Cortex 43, 5-21. doi: 10.1016/S0010-9452(08)70442-8

Sawyer, K. (2011). The cognitive neuroscience of creativity: a critical review. Creat. Res. J. 23, 137-154. doi: 10.1080/10400419.2011.571191

Schacter, D. L., Addis, D. R., and Buckner, R. L. (2007). Remembering the past to imagine the future, the prospective brain. Nat. Rev. Neurosci. 8, 657-661. doi: 10.1038/nrn2213

Seger, C. A., Desmond, J., Glower, G., and Gabrieli, J. D. (2000). Functional magnetic resonance imaging evidence for righthemisphere involvement in processing unusual semantic relationships. Neuropsychology 14, 361-369. doi: 10.1037/0894-4105. 14.3.361

Seghier, M. L., Fagan, E., and Price, C. J. (2010). Functional subdivisions in the left angular gyrus where the semantic system meets and diverges from the default network. J. Neurosci. 30, 16809-16817. doi: 10.1523/JNEUROSCI.3377-10.2010

Shah, C., Erhard, K., Ortheil, H.-J., Kaza, E., Kessler, C., and Lotze, M. (2011). Neural correlates of creative writing: an fMRI Study. Hum. Brain Mapp. 34, 1088-1101. doi: 10.1002/hbm. 21493

Shamay-Tsoory, S. G., Adler, N., Aharon-Peretz, J., Perry, D., and Mayseless, N. (2011). The origins of originality, the neural bases of creative thinking and originality. Neuropsychologia 49, 178-185. doi: 10.1016/j.neuropsychologia.2010. 11.020

Siebörger, F. T., Ferstl, E. C., and von Cramon, D. Y. (2007). Making sense of nonsense: an fMRI study of task induced inference processes during discourse comprehension. Brain Res. 1166, 77-91. doi: 10.1016/j.brainres.2007. 05.079

Smith, E. E., and Jonides, J. (1999). Storage and executive processes in the frontal lobes. Science 283, 1657-1661. doi: 10.1126/science.283.5408.1657

Smith, R., Keramatian, K., and Christoff, K. (2007). Localizing the rostrolateral prefrontal cortex at the individual level. Neuroimage 36, 1387-1396. doi: 10.1016/j.neuroimage.2007.04.032

Sternberg, R. J., and Lubart, T. (1999). "The concept of creativity, prospects and paradigms," in Handbook of Creativity, ed R. J. Sternberg (Cambridge: Cambridge University Press), 3-15.

Szpunar, K. K., Chan, J. C., and McDermott, K. B. (2009). Contextual processing in episodic future thought. Cereb. Cortex 19, 1539-1548. doi: 10.1093/cercor/ bhn191
Takeuchi, H., Taki, Y., Sassa, Y., Hashizume, H., Sekiguchi, A. Fukushima, A., et al. (2010a). Regional gray matter volume of dopaminergic system associate with creativity, evidence from voxelbased morphometry. Neuroimage 51, 578-585. doi: 10.1016/j. neuroimage.2010.02.078

Takeuchi, H., Taki, Y., Sassa, Y., Hashizume, H., Sekiguchi, A. Fukushima, A., et al. (2010b) White matter structures associated with creativity, evidence from diffusion tensor imaging. Neuroimage 51, 11-18. doi: 10.1016/j.neuroimage. 2010.02.035

Talairach, J., and Tournoux, P. (1988). Co-Planar Stereotaxic Atlas of the Human Brain. New York: Thieme.

Thompson-Schill, S. L. (2003). Neuroimaging studies of semantic memory, inferring "how" from "where." Neuropsychologia 41, 280-292. doi: 10.1016/S0028-3932 (02)00161-6

Thompson-Schill, S. L., and Botvinick, M. M. (2006). Resolving conflict, a response to Martin and Cheng (2006). Psychon. Bull. Rev. 13, 402-408. discussion: 09-11. doi: 10.3758/BF03193860

Thompson-Schill, S. L., D'Esposito, M., Aguirre, G. K., and Farah, M. J. (1997). Role of left inferior prefrontal cortex in retrieval of semantic knowledge, a reevaluation. Proc. Natl. Acad. Sci. U.S.A. 94, 14792-14797. doi 10.1073/pnas.94.26.14792

Tian, F., Tu, S., Qiu, J., Lv, J. Y., Wei, D. T., Su, Y. H., et al. (2011). Neural correlates of mental preparation for successful insight problem solving. Behav. Brain Res. 216, 626-630. doi 10.1016/j.bbr.2010.09.005

Torrance, E. P. (1979). Torrance Tests of Creative Thinking, Bensenville, IL: Scholastic Testing Service Inc.

Tsuchida, A., and Fellows, L. K. (2009). Lesion evidence that two distinct regions within prefrontal cortex are critical for n-back performance in humans. J. Cogn Neurosci. 21, 2263-2275. doi: 10.1162/jocn.2008.21172

Turkeltaub, P. E., Eickhoff, S. B., Laird, A. R., Fox, M., Wiener, M., and Fox, P. (2012). Minimizing within-experiment and withingroup effects in Activation Likelihood Estimation metaanalyses. Hum. Brain Mapp. 33, 1-13. doi: 10.1002/hbm.21186

Van Hoeck, N., Ma, N., Ampe, L., Baetens, K., Vandekerckhove, M., and Overwalle, F. V. (2013). Counterfactual thinking, an fMRI study on changing the past for a better future. Soc. Cogn. Affect. Neurosci. 8, 556-564. doi: $10.1093 / \mathrm{scan} / \mathrm{nss} 031$

Vartanian, O. (2012). Dissociable neural systems for analogy and metaphor: implications for the neuroscience of creativity. $\mathrm{Br}$. J. Psychol. 103: 302-316. doi: 10.1111/j.2044-8295.2011.02073.x

Vartanian, O., and Goel, V. (2005). Task constraints modulate activation in right ventral lateral prefrontal cortex. Neuroimage 27, 927-933. doi: 10.1016/j.neuroimage.2005.05.016

Vigneau, M., Beaucousin, V., Hervé, P.-Y., Jobard, G., Petit, L., et al. (2010). What is right-hemisphere contribution to phonological, lexico-semantic, and sentence processing?, Insights from a metaanalysis. Neuroimage 54, 577-593. doi: $\quad 10.1016 /$ j.neuroimage.2010. 07.036

Volle, E., de Lacy Costello, A., Coates, L. M., McGuire, C., Towgood, K., Gilbert, S., et al. (2012). Dissociation between verbal response initiation and suppression after prefrontal lesions. Cereb. Cortex 22, 2428-2440. doi: 10.1093/ cercor/bhr322

Volle, E., Gonen-Yaacovi, G., de Lacy Costello, A., Gilbert, S. J., and Burgess, P. W. (2011). The role of rostral prefrontal cortex in prospective memory, a voxel-based lesion study. Neuropsychologia 49, 2185-2198. doi: 10.1016/ j.neuropsychologia.2011.02.045

Volle, E., Kinkingnehun, S., Pochon, J. B., Mondon, K., Thiebaut de Schotten, M., Seassau, M., et al. (2008). The functional architecture of the left posterior and lateral prefrontal cortex in humans. Cereb. Cortex 18, 2460-2469. doi: 10.1093/cercor/bhn010

Volle, E., Pochon, J. B., Lehericy, S., Pillon, B., Dubois, B., and Levy, R. (2005). Specific cerebral networks for maintenance and response organization within working memory as evidenced by the 'double delay/double response' paradigm. Cereb. Cortex 15, 1064-1074. doi: 10.1093/cercor/bhh207

Wagner, A. D., Paré-Blagoev, E. J., Clark, J., and Poldrack, R. A. (2001). Recovering meaning, left prefrontal cortex guides controlled semantic retrieval. Neuron 31, 329-338. doi: 10.1016/S0896-6273 (01)00359-2

Walther, S., Goya-Maldonado, R., Stippich, C., Weisbrod, M., and Kaiser, S. (2010). A supramodal network for response inhibition. Neuroreport 21, 191-195. doi: 10.1097/WNR.0b013e328335640f 
Ward, T. B. (2007). Creative cognition as a window on creativity. Methods 42, 28-37. doi: $\quad$ 10.1016/j.ymeth.2006. 12.002

Ward, T. B., and Kolomyts, Y. (2010). "Cognition and creativity," in The Cambridge Handbook of Creativity, eds J. Kaufman and R. Sternberg (New York, NY: Cambridge University Press), 93-112. doi: 10.1017/CBO97805117 63205.008

Wendelken, C., and Bunge, S. A. (2010). Transitive inference, distinct contributions of rostrolateral prefrontal cortex and the hippocampus. J. Cogn. Neurosci. 22, 837-847. doi: 10.1162/jocn.2009. 21226
Wendelken, C., Nakhabenko, D., Donohue, S. E., Carter, C. S., and Bunge, S. A. (2008). "Brain is to thought as stomach is to ??” investigating the role of rostrolateral prefrontal cortex in relational reasoning. J. Cogn. Neurosci. 20, 682-693. doi: 10.1162/jocn.2008. 20055

Wharton, C. M., Grafman, J., Flitman, S. S., Hansen, E. K., Brauner, J., Marks, A., et al. (2000). Toward neuroanatomical models of analogy, a positron emission tomography study of analogical mapping. Cogn. Psychol. 40, 173-197. doi: 10.1006/ cogp.1999.0726

Xue, G., Aron, A. R., and Poldrack, R. A. (2008). Common neural substrates for inhibition of spoken and manual responses. Cereb. Cortex 18, 1923-1932. doi: 10.1093/cercor/ bhm 220

Zeki, S. (2001). Essays on science and society. Artistic creativity and the brain. Science 293, 51-52. doi: 10.1126/science. 1062331

Conflict of Interest Statement: The authors declare that the research was conducted in the absence of any commercial or financial relationships that could be construed as a potential conflict of interest.

Received: 30 April 2013; paper pending published: 31 May 2013; accepted: 26 July 2013; published online: 14 August 2013.
Citation: Gonen-Yaacovi G, de Souza $L C$, Levy $R$, Urbanski $M$, Josse $G$ and Volle E (2013) Rostral and caudal prefrontal contribution to creativity: a meta-analysis of functional imaging data. Front. Hum. Neurosci. 7:465. doi: 10.3389/fnhum.2013.00465

Copyright (C) 2013 Gonen-Yaacovi, de Souza, Levy, Urbanski, Josse and Volle. This is an open-access article distributed under the terms of the Creative Commons Attribution License (CC BY). The use, distribution or reproduction in other forums is permitted, provided the original author(s) or licensor are credited and that the original publication in this journal is cited, in accordance with accepted academic practice. No use, distribution or reproduction is permitted which does not comply with these terms. 